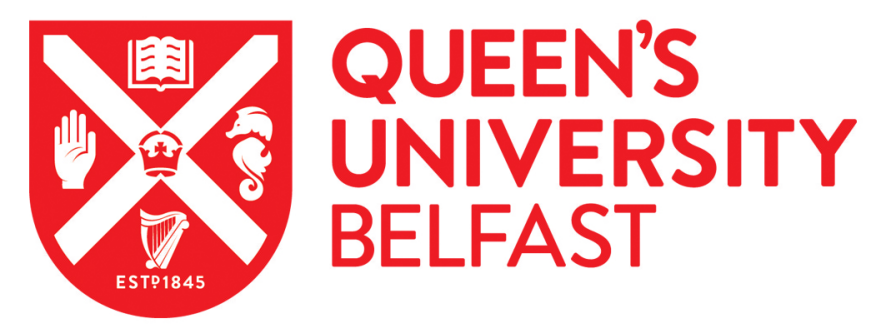

\title{
Notched response of non-crimp fabric thin-ply laminates
}

Arteiro, A., Catalanotti, G., Xavier, J., \& Camanho, P. P. (2013). Notched response of non-crimp fabric thin-ply laminates. Composites Science and Technology, 79, 97-114. https://doi.org/10.1016/j.compscitech.2013.02.001

\author{
Published in: \\ Composites Science and Technology
}

\section{Document Version:}

Peer reviewed version

Queen's University Belfast - Research Portal:

Link to publication record in Queen's University Belfast Research Portal

\section{Publisher rights}

Copyright 2013 Elsevier.

This manuscript is distributed under a Creative Commons Attribution-NonCommercial-NoDerivs License

(https://creativecommons.org/licenses/by-nc-nd/4.0/), which permits distribution and reproduction for non-commercial purposes, provided the author and source are cited.

\section{General rights}

Copyright for the publications made accessible via the Queen's University Belfast Research Portal is retained by the author(s) and / or other copyright owners and it is a condition of accessing these publications that users recognise and abide by the legal requirements associated with these rights.

\section{Take down policy}

The Research Portal is Queen's institutional repository that provides access to Queen's research output. Every effort has been made to ensure that content in the Research Portal does not infringe any person's rights, or applicable UK laws. If you discover content in the Research Portal that you believe breaches copyright or violates any law, please contact openaccess@qub.ac.uk. 


\title{
Notched response of non-crimp fabric thin-ply laminates
}

\author{
A. Arteiro ${ }^{\text {a }}$, G. Catalanotti ${ }^{\mathrm{a}}$, J. Xavier ${ }^{\mathrm{b}}$, P.P. Camanho, ${ }^{\mathrm{a}, *}$ \\ ${ }^{a}$ DEMec, Faculdade de Engenharia, Universidade do Porto, Rua Dr. Roberto Frias, 4200-465 Porto, Portugal \\ ${ }^{b}$ CITAB, Universidade de Trás-os-Montes e Alto Douro, Engenharias I, Apartado 1013, 5001-801 Vila Real, Portugal
}

\begin{abstract}
This paper presents an experimental investigation of the mechanical response of a new class of advanced composite materials manufactured using thin non-crimp fabrics. Tensile and compressive tests in both unnotched and notched specimens were performed using two different lay-ups. The notched tests were based on specimens with central cracks and with circular holes, loaded in tension and compression. Digital image correlation was used to monitor the onset and propagation of damage on the surface plies. The results show that the lay-up with blocked plies and with higher differences in fiber orientation angles between consecutive plies has lower unnotched strength. However, due to the larger fracture process zone observed in the notched tests, such lay-up has marginally higher notched strengths. A size effect on the strength was observed for both the open-hole tension and compression tests. The size effect and the associated notch sensitivity of thin non-crimp fabrics were similar to those observed in typical aerospace grade unidirectional pre-impregnated composite materials. It is also concluded that the thin non-crimp fabrics exhibit an improved response to bolt-bearing loads over traditional composite materials.
\end{abstract}

Keywords:

A. Laminates, B. Stress concentrations, D. Mechanical testing, E. Tow.

\section{Introduction}

When developing new manufacturing technologies and new types of composite materials, understanding their potential benefits and drawbacks with respect to manufacturing, processing, material properties, design, cost-effectiveness, and life-cycle assessment is extremely important to ensure their successful introduction in the market. Due to the increasing use of carbon fiber reinforced polymers (CFRP) in airframes, when promising new composite technologies appear aircraft manufacturers try to follow up their development, aiming to improve the performance of aircraft structures. One new technology of interest is the spread tow thin-ply technology, which is able to continuously and stably open fiber tows, and to produce flat and straight plies with dry ply thicknesses as low as $0.02 \mathrm{~mm}$.

The tow-spreading technology, originally developed by Kawabe et al. [1] at the Industrial Technology Center in Fukui Prefecture (Fukui-city, Japan), consists of a roll part for the preliminary opening of the original tow, followed by a pneumatic part which continuously spreads it until the required dry ply thickness. According to Sihn et al. [2], widely opened tows can be cost-effectively obtained from thick tows, such as $12 \mathrm{k}$ filament tows, without damaging the fibers. In the pneumatic

\footnotetext{
*Corresponding author

Email address: pcamanho@fe.up.pt (P.P. Camanho)
} 
part, where the main opening takes place, thick tows are spread by means of an uniform airflow through sagged fiber filaments. The air flows through an air duct with the help of vacuum, and the tow sags towards the airflow direction. As the tow spreading begins, air flows between the filaments, helping the tow to spread more and faster. The wider the tow is spread, the thinner the tow thickness becomes.

To meet the growing demands of enhanced damage resistance and tolerance, and improved outof-plane properties, together with low manufacturing costs and easier handling and storage without sacrificing the in-plane elastic and strength properties, non-crimp fabrics (NCF) have been developed and proposed as reliable substitutes of both traditional unidirectional (UD) prepreg tapes and crimp textile configurations. When compared with UD prepreg laminates, only a slight reduction of the in-plane elastic and strength properties caused by the yarns is observed [3, 4].

Until recently, multiaxial carbon reinforcements were produced with areal weights equal to or higher than $200 \mathrm{~g} / \mathrm{m}^{2}$ [5]. Combining multiaxial and tow-spreading technologies, new textile reinforcements with low areal weights can be developed, opening new possibilities and concepts for the design of composite laminates. One of these concepts consists of biaxial carbon reinforcements with low areal weights and low angles, the trademarked Chomarat C-PLY ${ }^{\mathrm{TM}}$. This new bi-angle thinply NCF material based on lay-ups such as [0/25] or [0/45] is particularly suitable for application to many components subjected to combined bending and twisting loads and deformations, such as wings, stabilizers, turbine fans, wind turbine or helicopter rotor blades, propellers, shafts, torsional rods, and many sporting goods $[6,7]$.

The use of thin-ply laminates with fewer ply angles makes laminate homogenization much easier, leading to many benefits for laminate design and optimization. Indeed, use of homogenized, asymmetric laminates can result in weight and cost savings, since continuous and simpler lay-up becomes possible, reducing processing time, costs, waste and stacking errors, and still ensures homogenized stiffness and strength and practically zero thermal warpage $[8,9]$.

Other advantages of using thin-ply laminates include (i) higher fiber dispersion and uniformity of plies [10], resulting in stronger laminates due to the improved resistance to matrix cracking and delamination, and conducting to less resin rich areas, (ii) potential to use heavier tow yarns [5], such as $100 \mathrm{k}$ and $200 \mathrm{k}$, to cost-effectively obtain spread tows, and (iii) improved surface appearance [5] due to the unique uniformity of the tow spreading.

In addition to the benefits regarding laminated composites design using tow-spread thin-plies outlined in the previous points, the potential advantages with respect to the structural integrity of these materials must also be addressed. Therefore, the objective of this paper is to study the mechanical response of composite laminates manufactured using thin plies.

An extensive experimental test program is conducted, including investigations on the notched strength, size effects, brittleness, and bearing strength of thin-ply laminates obtained from towspreading. Particular emphasis is given to the damage mechanisms and failure modes of these materials, assessed by means of digital image correlation. A comparison with typical aerospace grade CFRP will define the relative performance of the thin-ply laminates.

\section{Experimental test program}

\subsection{Material selection and manufacturing}

The material used in this experimental program is the carbon NCF C-PLY ${ }^{\mathrm{TM}}$ T700/AR-2527 epoxy system prepreg material from Aldila (material reference P/N C-PLY BX 0/-45 150 T3,4 12K 
HS-AR2527). This prepreg material includes the tow-spread C-PLY ${ }^{\mathrm{TM}} \mathrm{T} 700[0 /-45] \mathrm{NCF}$ from Chomarat, with an areal weight of $150 \mathrm{~g} / \mathrm{m}^{2}$ per bi-angle layer (or $75 \mathrm{~g} / \mathrm{m}^{2}$ per ply). Table 1 shows the ply properties of the tow-spread thin-ply C-PLY ${ }^{\mathrm{TM}} \mathrm{T} 700[0 /-45]$ NCF from Chomarat, for a fiber volume fraction around $50 \% . E_{1}$ and $E_{2}$ are respectively the longitudinal and transversal Young's moduli, $G_{12}$ is the shear modulus, $\nu_{12}$ is the major Poisson's ratio, $X_{T}$ and $X_{C}$ are respectively the longitudinal tensile and compressive strengths, $Y_{T}^{u d}$ and $Y_{C}$ are respectively the transverse tensile and compressive strengths, $S_{L}^{u d}$ is the in-plane shear strength, $V_{f}$ is the fiber volume fraction, and $E_{f}$ and $X_{f}$ are respectively the T700 carbon fiber's Young's modulus and tensile strength.

[Table 1 about here.]

Two different thin-ply laminates are investigated. The first one, hereafter referred to as lay-up 1 , is a $[(0 /-45) /(90 / 45)]_{6 \mathrm{~T}} 24$-ply thick asymmetric laminate with a nominal laminate thickness of $2.0 \mathrm{~mm}$. Lay-up 1 is made with $15.24 \mathrm{~cm}(6 ")$ wide C-PLY ${ }^{\mathrm{TM}}$ [0/ - 45] NCF bi-angle strips and $1.27 \mathrm{~cm}(1 / 2 ")$ stagger, with seams, i.e., for each C-PLY ${ }^{\mathrm{TM}}$ NCF bi-angle layer, every $15.24 \mathrm{~cm}$ the $-45^{\circ}$ plies have seams. The second thin-ply laminate, hereafter referred to as lay-up 2 , is a $[(0 /-45) /(45 / 0) /(90 / 45) /(-45 / 90)]_{\mathrm{S}}$ 16-ply thick laminate with a nominal laminate thickness of $1.3 \mathrm{~mm}$, without seams. Note that lay-up 2 is symmetric by C-PLY ${ }^{\mathrm{TM}}[0 /-45] \mathrm{NCF}$ bi-angle layer, but not-symmetric by ply. For both thin-ply laminates, the nominal ply thickness is $0.08 \mathrm{~mm}$. The $0^{\circ}$ fiber orientation is coincident with the loading direction.

These laminates were manufactured at VX Aerospace using vacuum bagging. After curing, each panel was cut to the specimens' nominal dimensions using a diamond-coated disk.

\subsection{Instrumentation}

Strain gages were used to measure local strain values, whereas digital image correlation (DIC) was used to evaluate the surface displacement and strain fields of the specimens, by means of a singlecamera. The ARAMIS DIC-2D v6.0.2 developed by GOM [11], equipped with an 8-bit Baumer 138 Optronic FWX20 camera (resolution of $1624 \times 1236$ pixels $^{2}$, pixel size of 4.4 microns, and sensor format of 1/1.8"), was used. The digital camera was coupled with a Nikon AF Micro-Nikkor $200 \mathrm{~mm}$ f/4D IF-ED lens for image grabbing, together with one (plain strength tension tests, center-notched tension tests, and open-hole tension tests with a hole diameter of $10 \mathrm{~mm}$ ) or two (open-hole tension tests with a hole diameter of $3 \mathrm{~mm}$, and open-hole compression tests) extension tubes of $20 \mathrm{~mm}$. The working distance (defined between the specimen's surface and the support of the camera) was set to $1371 \mathrm{~mm}$ for both plain strength and center-notched tensile tests, $90 \mathrm{~mm}$ and $1760.7 \mathrm{~mm}$ for the open-hole tensile tests with hole diameters of $3 \mathrm{~mm}$ and $10 \mathrm{~mm}$, respectively, and $564 \mathrm{~mm}$ and $646 \mathrm{~mm}$ for the open-hole compressive tests with hole diameters of $2 \mathrm{~mm}$ and $7 \mathrm{~mm}$, respectively.

The lens was adjusted to be in focus with regard to the surface of interest, and the lens aperture was then closed to $f / 11$ in all tests to improve the depth of field. The shutter time was set to $10 \mathrm{~ms}$ for both plain strength and center-notched tensile tests, $6 \mathrm{~ms}$ and $16 \mathrm{~ms}$ for the open-hole tensile tests with hole diameters of $3 \mathrm{~mm}$ and $10 \mathrm{~mm}$, respectively, and 2.5-4 ms and $6 \mathrm{~ms}$ for the open-hole compressive tests with hole diameters of $2 \mathrm{~mm}$ and $7 \mathrm{~mm}$, respectively. The captured region was of approximately $33 \times 43 \mathrm{~mm}^{2}$ for both plain strength and center-notched tensile tests (conversion factor of $0.0265 \mathrm{~mm} / \mathrm{pixel}$ ), $13 \times 18 \mathrm{~mm}^{2}$ and $43 \times 56 \mathrm{~mm}^{2}$ for the open-hole tensile tests with hole diameters of $3 \mathrm{~mm}$ and $10 \mathrm{~mm}$ (conversion factors of $0.0109 \mathrm{~mm} /$ pixel and $0.0346 \mathrm{~mm} /$ pixel), respectively, and $11 \times 15 \mathrm{~mm}^{2}$ and $15 \times 19 \mathrm{~mm}^{2}$ for the open-hole compressive tests with hole diameters of $2 \mathrm{~mm}$ and $7 \mathrm{~mm}$ (conversion factors of $0.0090 \mathrm{~mm} /$ pixel and $0.0117 \mathrm{~mm} /$ pixel), respectively. 
The measuring parameters used in the DIC analyses were a facet size and a facet step of $15 \times 15$ pixels $^{2}$ and a strain base length of 5 subsets. This configuration leads to a displacement resolution in the order of $10^{-2}$ and a strain resolution of about $0.01-0.05 \%$ [12].

For lay-up 1, the displacement and strain fields were measured in a $45^{\circ}$ ply, whereas for lay-up 2 , the displacement and strain fields were measured in a $0^{\circ}$ ply (remember that this laminates are asymmetric). With such analysis, it is possible to assess the stress concentrations and transverse cracking onset and propagation on the surface plies.

All tests were performed under displacement control, at a controlled speed of $2.0 \mathrm{~mm} / \mathrm{min}$, in a servohydraulic MTS 810 testing machine, using a $100 \mathrm{kN}$ load cell. The acquisition frequency was 5 Hz.

\subsection{Plain strength tests}

The knowledge of the laminate elastic properties and unnotched strengths is essential in the mechanical characterization of a composite material, and it is a required parameter for failure criteria, as well as for analytical and numerical models. Both unnotched tension and compression tests were performed. The specimens' nominal width $(W)$ is $25 \mathrm{~mm}$ and the specimens' nominal length $(L)$ is $250 \mathrm{~mm}$ for the tensile tests and $305 \mathrm{~mm}$ for the compressive tests.

One tensile test specimen per laminate configuration was instrumented with two strain gages, placed along the longitudinal and transversal directions near the center of the specimen. The DIC technique was used to asses transverse cracking formation near the free-edges in one specimen per laminate.

Following the ASTM standard [13], a special test rig designed to prevent buckling was used in the compressive tests. One specimen per laminate configuration was instrumented with two strain gages, both placed along the longitudinal direction in the center of the specimen, but in opposite faces. This configuration was chosen to assess if non-negligible bending occurs.

\subsection{Center-notched tests}

Center-notched tests are typically used to measure the laminate's fracture toughness. This property is required to assess the brittleness of the laminate and it is required for the strength prediction of open-hole laminates loaded in tension and compression [14]. Therefore, both notched tension and notched compression experimental tests were conducted. The specimens' nominal width $(W)$ is $30 \mathrm{~mm}$ and the specimens' nominal length $(L)$ is $250 \mathrm{~mm}$ for the tensile tests and $305 \mathrm{~mm}$ for the compressive tests. The nominal length of the notch $(2 a)$ is $4 \mathrm{~mm}$.

The central notch was obtained using a milling machine, ensuring a distance of $1 \mathrm{~mm}$ between the notch faces. The notch tip was not sharpened, since, based on the previous work of Camanho and Catalanotti [14], no relevant difference between the fracture toughness of specimens with and without sharpened notch tips is expected.

One specimen per laminate type was instrumented with one strain gage, placed along the longitudinal direction at the center of the specimen. The DIC technique was used to assess transverse cracking formation near the notch tips in one specimen per lay-up.

In the center-notched compressive tests, a special test rig designed to prevent buckling [13] was used. One specimen per lay-up was instrumented with two strain gages, both placed along the longitudinal direction near the central notch, but on opposite faces of the specimen. This configuration was chosen to assess if bending occurs. 
The laminate tensile and compressive fracture toughness, $\mathcal{K}_{T}^{L}$ and $\mathcal{K}_{C}^{L}$ respectively, are obtained using the laminate remote tensile stress at failure, $\bar{\sigma}_{T}^{\infty}$, according to the equations presented in [14].

From the laminate fracture toughness, it is possible to estimate the fracture toughness of the $0^{\circ}$ plies $\left(\mathcal{K}_{T}^{0}\right.$ for tension and $\mathcal{K}_{C}^{0}$ for compression), using the analytical model proposed by Camanho and Catalanotti [14]. This analytical closed-form solution based on fracture mechanics and lamination theory was originally developed for symmetric, balanced laminates in tension, though applied here to asymmetric laminates in tension and compression. In addition, it should be noted that the analytical closed-form solution is valid for materials and lay-ups that have small delaminated regions and small fracture process zones at the vicinity of the notch tip.

\subsection{Open-hole tests}

Open-hole tests are typically used to study the mechanical response of composite laminates with stress concentrations and to assess the effect of size on the strength. In addition, these tests are important for the definition of material/lay-up and geometric parameters, such as the characteristic distance, used in semi-empirical closed-form models such as the point stress and average stress models [15], which are used in the prediction of the notched strength of composite laminates.

Open-hole tests, in both tension and compression, are used here to evaluate the mechanical response of thin-ply laminates in the presence of stress concentrations, and to study the effects of size when the specimens are subjected to tensile or compressive loads. The results of the experimental tests will be used in future work to validate the solutions of closed-form models used to predict the notched response of thin-ply laminates.

Table 2 shows the open-hole test matrix, where $W$ is the nominal width, $d$ is the nominal hole diameter, and $L$ is the nominal length. A width-to-diameter ratio $W / d=4$ is used.

[Table 2 about here.]

For the open-hole tensile tests, one specimen per laminate configuration and per geometry was instrumented with one strain gage placed along the longitudinal direction, away from the central hole. As before, the DIC technique was used to assess transverse cracking formation near the holes in the specimens with hole diameters of $3 \mathrm{~mm}$ and $10 \mathrm{~mm}$.

A test rig designed to prevent buckling [13] was used in the open-hole compression tests. One specimen per lay-up and per geometry was instrumented with two strain gages, both placed in the longitudinal direction near the central hole, but on opposite faces of the specimen. With this configuration, it is possible to assess if buckling occurs. The DIC technique was used to track transverse cracking formation near the hole edges in the specimens with hole diameters of $2 \mathrm{~mm}$ and $7 \mathrm{~mm}$.

\subsection{Bearing tests}

Bolt-bearing tests were performed following the ASTM D 5961 test standard [16]. The purpose of bolt-bearing tests is to evaluate the mechanical behavior of thin-ply laminates when subjected to local compressive efforts, typical of mechanically fastened joints. These tests were performed in specimens with a nominal hole diameter $d=6 \mathrm{~mm}$, end distance to hole diameter ratio $e / d=6$, width to hole diameter ratio $W / d=6$, and nominal length $L=215 \mathrm{~mm}$. A bolt M6 was used with washers subjected to a torque $T=2.2 \mathrm{Nm}$.

One specimen per laminate was instrumented with one strain gage placed in the longitudinal direction away from the bearing region. 
The laminate bearing stress, $\sigma^{b}$, is defined as [16],

$$
\sigma^{b}=\frac{P}{d t}
$$

where $P$ is the load, $d$ is the hole diameter, and $t$ is the nominal thickness of the specimen. The bearing strength, $\bar{\sigma}^{b}$, is defined as the bearing stress at first load drop $\left(\bar{\sigma}^{b}=\left.\sigma^{b}\right|_{\text {1st load drop }}\right)$.

\section{Experimental test results}

\subsection{Plain strength test results}

The plain strength test results, for both tension and compression, are shown in figure 1. Both stress-displacement and stress-strain relations are represented. Note that the longitudinal strains $\left(\varepsilon_{L}\right)$ for both tension and compression (figure 1(b)) are not failure strains, since the maximum tensile and compressive strains of the strain gages (about $5000 \mu \mathrm{m} / \mathrm{m}$ and $-7000 \mu \mathrm{m} / \mathrm{m}$, respectively) were reached. Note also that in the unnotched compression test one of the strain gages installed in the lay-up 2 instrumented specimen did not work properly, and just one stress-longitudinal strain relation is represented for this laminate.

[Figure 1 about here.]

As shown in figure 1(a), for the unnotched tension tests both thin-ply laminates exhibit a linear behavior nearly up to the ultimate failure stress, and no nonlinearity is observed before the peak load. These results suggest that extensive transverse cracking and delamination did not occur before final failure, which is dominated by fiber breakage. For the lay-up 1 specimens - figure 2(a) failure occurred in two different places, as a result of the highly catastrophic failure mode. A brittle type of net-section failure mode can be observed, whose failure section is perpendicular to the applied load. Delamination was not observed in the specimens. On the other hand, figure 2(b) shows that the lay-up 2 specimens exhibit a pull-out failure mode, where some splitting and delamination can be observed.

[Figure 2 about here.]

Figure 1(a) also shows that the stress-displacement relations for both thin-ply laminates tested under compression exhibit a nonlinear behavior, suggesting that permanent damage or generalized plastic deformation develops before final failure. Figure 1(b) shows that the stress-longitudinal strain relations of both strain gages for the lay-up 1 specimen are similar, indicating that buckling did not occur. Based in the similarity between the stress-longitudinal strain relations for the lay-up 1 and lay-up 2 specimens, it can be assumed that buckling also did not occur in the lay-up 2 specimens.

Observing the failed compressive specimens, figure 3, it is noted that both laminates exhibit a net-section failure mode. The fracture planes of both laminates are inclined with respect to the laminate midplane, and fiber kinking is observed. However, lay-up 1 specimens - figure 3(a) exhibit a more brittle failure plane, since an almost clean failure surface is observed, dominated by fiber fracture, including complete separation of the two parts of the specimens. On the other hand, lay-up 2 specimens - figure 3(b) - exhibit a more irregular failure surface, dominated by fiber kinking and matrix fracture, with some fibers still connecting both parts of the broken specimens. 
The slightly different failure modes observed in the thin-ply unnotched specimens tested in tension and compression result from their different stacking sequences. Unlike lay-up 1, whose relative orientation of the adjacent plies is $45^{\circ}$ (within and between the [0/ - 45] bi-layers), in lay-up 2 the adjacent $[0 /-45]$ bi-layers are stacked either with relative ply orientations of $90^{\circ}$, conducting to higher interlaminar stress concentrations, or with the same ply orientation, i.e. two adjacent plies with the same fiber orientation are "blocked" together, conducting to higher stress concentrations in the adjacent interfaces and to lower in-situ strengths [17]. The combination of the effects of higher relative ply orientations and ply "blocking" increases the interlaminar stresses, and consequently triggers other damage mechanisms, including delamination onset, pull-out and splitting in tension, and earlier matrix cracking and fiber kinking in compression. Still, the extent of subcritical damage mechanisms observed in the lay-up 2 specimens is considerably lower than that observed in traditional prepreg quasi-isotropic CFRP laminates [18].

The mean values and standard deviations (STDV) of the unnotched strengths, and the elastic properties obtained in the unnotched tension tests are shown in tables 3 and 4 for lay-up 1 and lay-up 2, respectively. $X_{T}^{L}$ and $X_{C}^{L}$ are respectively the tensile and compressive unnotched strengths, $E^{L}$ is the laminate Young's modulus, and $\nu_{12}^{L}$ is the laminate major Poisson's ratio.

[Table 3 about here.]

[Table 4 about here.]

Observing the results in tables 3 and 4 it can be concluded that the brittle type of net-section failure mode exhibited by lay-up 1, resulting from its ability to delay subcritical damage mechanisms, is beneficial with respect to the plain strength of these CFRP laminates. Indeed, the tensile and compressive unnotched strengths for lay-up 2 are, respectively, $11.2 \%$ and $14.0 \%$ lower than those for lay-up 1. Such results may be a consequence of the higher interlaminar stresses and lower in-situ strengths of lay-up 2, which promote failure mechanisms before final failure.

An interesting aspect of the thin-ply laminates is the apparent ability to avoid transverse cracking. This can be observed in figure 4, which shows the surface longitudinal strain fields obtained with the DIC technique in the unnotched tension tests, corresponding to the load just before final failure. Figures 4(a) and (b) show the longitudinal strain $\left(\varepsilon_{x}\right)$ along two lines near the free-edges, oriented along the loading direction. A completely regular strain distribution would be expected; however, the oscillations of the strain values are very small. In fact, transverse cracking (which would correspond to a discontinuity in the strain field) starting at the free-edges is almost absent, with only one exception for lay-up 2, as it can be observed near the bottom free-edge, corresponding to transverse cracking onset (see the blue lines of figure 4(b)).

[Figure 4 about here.]

\subsection{Center-notched test results}

The center-notched test results for both tension and compression are shown in figures 5 and 6 , respectively. Both the remote stress-displacement and the remote stress-longitudinal strain relations are represented. Note that the longitudinal strain $\left(\varepsilon_{L}\right)$ for tension (figure $5(b)$ ) is not the failure strain, since the maximum tensile strain of the strain gage (generally around $5000 \mu \mathrm{m} / \mathrm{m}$ ) was reached. 
[Figure 5 about here.]

[Figure 6 about here.]

[Figure 7 about here.

Observing figure 7 it is clear that the damage zone of lay-up 2 (figure $7(\mathrm{~b})$ ) is more extensive than that of lay-up 1 (figure $7(\mathrm{a})$ ). It is also noted that, unlike the lay-up 1 center-notched specimen, where the damaged zone is characterized by a small crack approximately parallel to the central notch (i.e. perpendicular to the loading direction), the lay-up 2 center-notched specimen exhibits a much more complex damage zone, with extensive fiber and matrix damage, spreading in different directions.

For the center-notched compression tests, figure 6(a), the remote stress-displacement relations for both thin-ply laminates are also approximately linear up to final failure. Small load drops can also be observed, as well as some nonlinearities, in particular close to the peak loads, and generally with negligible effect on the stiffness of the thin-ply laminates. These small load drops and nonlinearities indicate the development of damage, mainly at the vicinity of the crack tip, whose propagation results in the final failure of the specimen.

Figures 8 and 9 show representative center-notched specimens after testing in tension and compression, respectively. As shown in figure 8(a), the lay-up 1 center-notched tension specimens exhibit a brittle type of net-section failure mode, whose failure section is either perpendicular to the applied tension direction or at approximately $45^{\circ}$. Delamination is precluded in this lay-up. The lay-up 2 center-notched tension specimens, shown in figure 8(b), exhibit a more complex failure section, characterized by pull-out and splitting. In addition, for this case, the failure sections are not so clearly defined, since some are oriented at approximately $45^{\circ}$, whereas others show failure propagating perpendicular to the loading direction on one side of the central notch and propagating at $\pm 45^{\circ}$ on the other side. Extensive delamination is not observed. Note that, despite the balanced nature of the thin-ply laminates, and due to the unstable type of fracture typical of the center-notched tension tests, damage may occur predominantly at the $\pm 45^{\circ}$ plies, and propagate in one of these directions, as it was observed for both thin-ply laminates.

[Figure 8 about here.]

[Figure 9 about here.]

For the center-notched compression specimens shown in figure 9 a net-section failure mode is observed for both thin-ply laminates. The fracture planes of both thin-ply laminates are inclined with respect to the laminate midplane, as it was observed for the unnotched specimens (figure 3 ). Fiber kinking was observed in both thin-ply laminates, though in a greater extent for lay-up 2. 
Tables 5 and 6 show for lay-up 1 and lay-up 2 respectively the mean values and standard deviations of the tensile and compressive remote stresses at failure, respectively $\bar{\sigma}_{T}^{\infty}$ and $\bar{\sigma}_{C}^{\infty}$, and the mean values and standard deviations of the laminate tensile and compressive fracture toughness, respectively $\mathcal{K}_{T}^{L}$ and $\mathcal{K}_{C}^{L}$. The predictions of the tensile and compressive fracture toughness of the $0^{\circ}$ plies, respectively $\mathcal{K}_{T}^{0}$ and $\mathcal{K}_{C}^{0}$, calculated using the analytical model proposed by Camanho and Catalanotti [14] are also shown.

[Table 5 about here.]

[Table 6 about here.]

The ability of thin-ply laminates to delay transverse cracking can be observed in the results of the center-notched tension tests. In figure 10 the surface longitudinal strain fields for lay-up 1 and lay-up 2 just before final failure are represented. In particular, the longitudinal strain along two lines near the notch tips, oriented along the loading direction, are shown. For lay-up 1, figure 10(a), a high strain concentration can be observed in a region confined to the notch tip, including a small discontinuity in one side of the notch (see the blue lines in figure 10(a)). For lay-up 2, figure 10(b), the high strain concentrations described previously for lay-up 1 are absent, since transverse cracking already propagated beyond both red and blue reference lines, and large discontinuities in the strain field near the notch tips can be observed. This is also a result of its stacking sequence, which leads to damage development near the notch (see also figure 8(b)). Still, for both thin-ply laminates, transverse cracking is restricted to the region near the notch tips, and, specially for lay-up 1, the extent of damage is very reduced, showing the ability of thin-ply laminates to delay transverse cracking, even in the presence of a notch.

[Figure 10 about here.]

Note that the greater extent of damage observed in lay-up 2 results in a stress relaxation near the notch tips before failure. This stress relaxation can be observed in figure 11, which shows the local stress-strain relations near the notch tips for lay-up 1 and lay-up 2. This local stress-strain relations were measured using the DIC technique as would be obtained by a strain gage placed at the locations highlighted in the left images of figures 11(a) and (b). In lay-up 2 (figure 11(b)), there is a sudden increase of the longitudinal strain in the stress-strain relation near the peak stress, indicating occurrence of stress relaxation. Such stress relaxation justifies the similar remote stresses at failure observed for both thin-ply laminates, despite the higher unnotched strength of lay-up 1.

[Figure 11 about here.]

Tables 5 and 6 , show that the tensile remote stress at failure and the laminate fracture toughness for lay-up 2 are only approximately $1 \%$ lower than those for lay-up 1 . On the other hand, the compressive remote stress at failure and the compressive laminate fracture toughness for lay-up 2 are approximately $5 \%$ higher than those for lay-up 1 . As expected, the damage developed in the vicinity of the notch before unstable crack propagation in the lay-up 2 center-notched specimens, which is suppressed in the lay-up 1 specimens, has a beneficial effect on the notched response of these laminates. With the development of such damage, either in the form of transverse cracking and delamination for tension or matrix cracking and fiber kinking for compression, stresses in the 
vicinity of the notch are redistributed, dissipating energy and decreasing the stress concentrations, ultimately resulting in an increase of the notched strength and fracture toughness of lay-up 2.

Regarding the predictions of the fracture toughness of the $0^{\circ}$ plies, shown in tables 5 and 6 , it should be noted that these values are not far from those typically obtained in CFRP laminates used in the aircraft and aerospace industries [14].

\subsection{Open-hole test results}

The open-hole test results for both tension and compression are shown in figures 12 and 13 , respectively.

[Figure 12 about here.]

[Figure 13 about here.]

As shown in figure 12, the remote stress-displacement relations for all the open-hole tension specimens are linear up to failure: no load drops are visible. However, for the lay-up 2 specimens with the $3 \mathrm{~mm}$ diameter hole (figure 12(a)), small load drops can be observed close to the peak loads, with negligible effect on the overall stiffness. These small load drops indicate the development of a fracture process zone near the hole, resulting in a more extensive damage zone before final failure, as shown in figure 14, where pictures taken in specimens with $d=3 \mathrm{~mm}$ and $d=10 \mathrm{~mm}$ just before their final failure are shown.

[Figure 14 about here.]

Figure 15 shows representative open-hole specimens tested to final failure. Both thin-ply laminates exhibit a brittle type of net-section failure mode, with a fracture plane perpendicular to the applied load. Some pull-out is observed in the lay-up 2 specimens, originating more irregular fracture surfaces.

[Figure 15 about here.]

For the open-hole compression tests, figure 13 shows that the remote stress-displacement relations for the lay-up 1 specimens are nonlinear, though not as pronounced as that observed for the unnotched compression tests. For the lay-up 2 specimens, nonlinearity is also observed in the corresponding remote stress-displacement relations, specially at loads close to the failure load. These nonlinear responses exhibited by both thin-ply laminates may result from the development of damage such as matrix cracking and/or fiber kinking, but also from buckling phenomena. Observing figure 16, it can be observed that the remote stress-longitudinal strain relations for both thin-ply laminates with $2 \mathrm{~mm}$ diameter holes have divergent paths, indicating occurrence of buckling in the window area of the anti-buckling rig. Buckling caused the premature failure of these open-hole specimens. Note that the occurrence of buckling in the specimens with the $2 \mathrm{~mm}$ diameter holes is the result of two factors, (i) the low thickness of the thin-ply laminates under investigation $(2.0 \mathrm{~mm}$ and $1.3 \mathrm{~mm}$ for lay-up 1 and lay-up 2, respectively), and (ii) the small width of these specimens, whose sides are not supported by the anti-buckling rig, making it ineffective to avoid out-of-plane bending. Accordingly, the results obtained in the specimens with a $2 \mathrm{~mm}$ hole are considered invalid and will not be taken into account in the subsequent discussion.

[Figure 16 about here.] 
Unlike the lay-up 1 specimens, where no load drops are identified, small load drops can be observed in the remote stress-displacement relations of the lay-up 2 specimens in compression, for all specimen configurations (hole sizes). These load drops occur close to the peak loads, with negligible effect on the stiffness, indicating that damage is developing in the vicinity of the hole.

Representative open-hole compression specimens after testing are shown in figure 17 for both thin-ply laminates. In all specimens, the macrocrack propagates from the hole boundary towards the edges of the specimens, and no relevant differences appear to exist between the failure modes of the two thin-ply laminates. Both exhibit some splitting, and delamination is almost absent.

[Figure 17 about here.]

Figures 15 and 17 show that both thin-ply laminates, either in tension and compression, exhibit a brittle type of net-section failure mode, with the failure plane perpendicular to the loading direction.

To further evaluate the differences in the development of damage in both thin-ply laminates, figures 18 and 19 show the surface longitudinal strain fields for the lay-up 1 and lay-up 2 openhole specimens with hole diameters of $3 \mathrm{~mm}$ and $10 \mathrm{~mm}$, loaded in tension. Figure 20 shows the surface longitudinal strain fields for both thin-ply laminates with the $7 \mathrm{~mm}$ diameter hole, loaded in compression. These results were obtained just before final failure.

[Figure 18 about here.]

[Figure 19 about here.]

[Figure 20 about here.]

Figure 18 shows that the open-hole specimens with the $3 \mathrm{~mm}$ diameter hole of both thin-ply laminates behave differently. For lay-up 2 (figure 18(b)), a substantially higher strain concentration can be observed near the hole, including a discontinuity in the strain field near the upper side of the hole (see the red lines), associated with transverse cracking. Such transverse cracking near the hole is not observed in lay-up 1 (figure 18(a)). These different responses can be further investigated observing figure 21, which shows the local stress-longitudinal strain relation near the hole, as would be obtained by a strain gage. Unlike lay-up 1 (figure 21(a)), which exhibits an approximately linear local stress-longitudinal strain relation near the hole up to final failure, lay-up 2 (figure 21(b)) exhibits local stress relaxation near the hole, since a sudden increase in the local strain can be observed before final failure.

\section{[Figure 21 about here.]}

Figure 19 indicates that the responses of the open-hole specimens with the $10 \mathrm{~mm}$ diameter hole for both thin-ply laminates are not substantially different. Both thin-ply laminates exhibit a small discontinuity near the hole (see the red lines), indicating onset of transverse cracking. However, no substantial stress relaxation is observed, as shown in figure 22. Notice only some instability of the local stress-longitudinal strain relation near the failure stress for lay-up 2 (figure 22(b)), resulting from the proximity of the damaged zone developed near the hole before failure.

[Figure 22 about here.] 
Comparing the results for the open-hole specimens with different hole diameters (figures 18 and 19), it can be seen that, in the case of the smaller specimens, the dimension of the damage zone cannot be neglected, unlike the larger specimens, whose dimensions are substantially higher than those of the damage zone. Observing the strain fields in the images on the left-hand side of figures 18(a) and (b), and figures 19(a) and (b), it can also be seen that transverse cracking at the straight free-edges is precluded in all specimen configurations.

For the open-hole specimens with the $7 \mathrm{~mm}$ diameter hole loaded in compression, it can be seen in figure 20 that the lay-up 1 specimen (figure 20(a)) shows a discontinuity in the strain field at the bottom side of the hole (see the blue lines), indicating cracking onset in that region. Since the strain distributions are very similar in those regions for both thin-ply laminates and no substantial difference was observed in the failed specimens, it seems that this discontinuity results from extemporaneous damage onset before final failure with no effect on the final results.

Tables 7 and 8 show respectively for lay-up 1 and lay-up 2 the mean values and standard deviations of the tensile and compressive remote stresses at failure, respectively $\bar{\sigma}_{T}^{\infty}$ and $\bar{\sigma}_{C}^{\infty}$, for each specimen geometry (i.e. hole diameter, $d$ ).

[Table 7 about here.]

[Table 8 about here.]

Following the tendency of the thin-ply center-notched specimens, and unlike what was observed in the unnotched test results, tables 7 and 8 show that the notched tensile strength for lay-up 2 is around 1-4\% greater than that for lay-up 1, whereas the notched compressive strength for lay-up 2 is around that for lay-up 1 (3.1\% greater for the specimens with the $5 \mathrm{~mm}$ diameter hole and $3.8 \%$ lower for the specimens with the $7 \mathrm{~mm}$ diameter hole). As mentioned before, the main cause of the opposite results observed in the unnotched and notched laminates is due to the damage that develops near the hole edge of lay-up 2 before failure, which relaxes the stresses near the hole and decreases stress concentrations. On the other hand, lay-up 1 limits such initial damage, resulting in a continuous increase of the stress near the hole until complete catastrophic failure.

The experimental results shown in tables 7 and 8 also clearly identify a size effect characterized by a decrease of the notched strength with increasing hole diameters. Indeed, increasing the hole diameter from $3 \mathrm{~mm}$ to $10 \mathrm{~mm}$ results in a decrease of the tensile notched strength of $15.1 \%$ for both thin-ply laminates, whereas increasing the hole diameter from $5 \mathrm{~mm}$ to $7 \mathrm{~mm}$ results in a decrease of the compressive notched strength of $7.8 \%$ and $14.0 \%$ for lay-up 1 and lay-up 2, respectively. The observed size effect is caused by the development of the fracture process zone, which redistributes stresses and dissipates energy. In small specimens, the size of the fracture process zone is nonnegligible when compared with the in-plane dimensions of the specimen, and the average stress at the fracture plane will tend to the unnotched strength of the laminate. On the other hand, in larger specimens, the relative size of the fracture process zone is very small and it is confined to the vicinity of the hole, resulting in a more brittle response.

The size effects can be further evaluated observing figure 23, which shows the normalized tensile (figure 23(a)) and compressive (figure 23(b)) notched strengths, defined as $\bar{\sigma}_{N}=\bar{\sigma}^{\infty} / X^{L}$, as a function of the hole diameter, $d$. In addition to the thin-ply laminates, the hole size effects for the $[90 / 45 / 0 /-45]_{3 \mathrm{~S}}(\mathrm{~L} 1)$ and $\left[90_{2} / 0_{2} / 45_{2} / 90_{2} / 0 / 45 /-45\right]_{\mathrm{S}}$ (L2) laminates manufactured in an autoclave using the T800/M21 unidirectional prepreg (nominal ply thickness of $0.133 \mathrm{~mm}$ ) [18], with 
hole diameters of $3 \mathrm{~mm}, 5 \mathrm{~mm}$ and $7 \mathrm{~mm}$, are also shown for comparison purposes. A constant width-to-diameter ratio $W / d=4$ was used in all laminates.

[Figure 23 about here.]

According to the experimental data shown in figure 23, the notched responses of the thin-ply lay-up 1 and T800/M21 L1 laminates are very similar, in particular for open-hole tension. For open-hole compression, the notched response of lay-up 1 is only slightly inferior to that of the T800/M21 L1 laminate. Note that these two laminates have the same number of plies and the same relative orientations between adjacent plies, though different ply thickness and different ply sequence (including laminate symmetry).

The same similarity in the notched responses can be observed for the thin-ply lay-up 2 and T800/M21 L2 laminates, both balanced as the previous ones, but comprising greater relative ply orientations, as well as ply "blocking". For open-hole tension, the notched response of lay-up 2 is slightly superior to that of the T800/M21 L2 laminate, in particular for the smaller hole diameters. For open-hole compression, the notched response of lay-up 2 is slightly inferior to that of the T800/M21 L2 laminate, in particular for the larger hole diameters. As mentioned previously, the later laminate configurations are more susceptible to subcritical damage, lowering the unnotched strengths, but also conducting to equivalent or improved notched responses, and therefore resulting in a substantially better mechanical performance in the presence of notches (see figure 23).

In order to evaluate the notch sensitivity of the thin-ply laminates, figure 24 shows the normalized tensile (figure 24(a)) and compressive (figure 24(b)) notched strengths as a function of the $d / W$ ratio. In addition to the tested thin-ply laminates, the experimental data available for the $[90 / 45 / 0 /-$ $45]_{3 \mathrm{~S}}(\mathrm{~L} 1)$ and $\left[90_{2} / 0_{2} / 45_{2} / 90_{2} / 0 / 45 /-45\right]_{\mathrm{S}}$ (L2) T800/M21 laminates (nominal ply thickness of $0.133 \mathrm{~mm}$ ) [18], and for the $[90 / 0 / 45 /-45]_{3 \mathrm{~S}}$ (L1) (hole diameters of 2, 4, 6, 8 and $10 \mathrm{~mm}$ ) and $[45 / 90 /-45 / 0]_{4 \mathrm{~S}}$ (L2) (hole diameters of 3.175, 6.35, 12.7 and 25.4 mm) IM7-8552 laminates (nominal ply thickness of $0.125 \mathrm{~mm}$ ), reported respectively in references [19] and [20], are also presented for comparison purposes. These figures also include the boundaries for notch-sensitive and notchinsensitive materials. For the notch-sensitive boundary, the normalized strengths are a function of the stress concentration factor $K_{T}\left(\bar{\sigma}_{N}=1 / K_{T}\right)$, defined in [21]. For a notch-insensitive material, the normalized strengths are a function of the geometry $\left(\bar{\sigma}_{N}=1-d / W\right)$. Note that the data points closer to the notch-sensitive boundary, for the same laminate, are the corresponding to the larger hole diameters.

[Figure 24 about here.]

Figure 24(a) indicates that the notch sensitivity of the thin-ply laminates in tension is lower or equivalent to that observed for the T800/M21 laminates. In addition, the notch sensitivity of the thin-ply laminates can be substantially lower than that of the IM7-8552 laminates, in particular when comparing with the IM7-8552 L2 laminate. In compression, despite the equivalent notch sensitivity for the thin-ply and T800/M21 laminates, the IM7-8552 L1 laminate is the one showing the lowest notch sensitivity.

It should be noted, however, that the laminate thickness effect was not taken into account in the previous discussions. According to Green et al. [20], independently of the laminate stacking sequence, an increase in the laminate thickness with constant hole diameter leads to a decrease of the failure stress, which approaches a constant value as the thickness increases. Therefore, the 
thin-ply laminates, in particular lay-up 2, may be benefiting from their lower thickness, whereas the higher notch sensitivity of the IM7-8552 L2 laminate may result from its higher laminate thickness.

It is also important to note that these NCF thin-ply laminates have a lower volume fraction $\left(V_{f}\right)$ than the T800/M21 and IM7-8552 laminates. In addition, unlike the latter, the NCF thin-ply laminates were not manufactured using autoclave/hotpress, but rather by vacuum bagging.

Taking into account the constraints mentioned before, these comparisons should be treated with some caution. Still, since no other experimental data is available regarding size effects on thin-ply laminates, in the following analyses these results will be taken as preliminary reference values, but keeping in mind that further investigations should be conducted to clarify these preliminary results.

\subsection{Bearing test results}

As expected, all specimens exhibited a bearing failure mode, resulting from local compressive damage in the bearing hole region. Representative specimens after testing are shown in figure 25. No relevant difference between the failure modes of both thin-ply laminates is observed.

[Figure 25 about here.]

The bolt-bearing test results for both thin-ply laminates are shown in figure 26. Figure 26(a) shows the normalized bearing stress, defined as $\sigma_{N}^{b}=\sigma^{b} / X_{C}^{L}$, as a function of displacement, for both thin-ply laminates. The results for a quasi-isotropic $[90 / 0 / \pm 45]_{3 \mathrm{~S}}$ IM7-8552 CFRP laminate (nominal ply thickness of $0.125 \mathrm{~mm}$ ), obtained in a previous work [23], are also shown. Figure 26(b) shows the bearing stress-longitudinal strain relations for the thin-ply laminates, obtained in the instrumented specimens.

[Figure 26 about here.]

The bearing stress-displacement relations shown in figure 26(a) for both thin-ply laminates are approximately linear only up to around $50 \%$ of the maximum bearing stress, exhibiting a slight nonlinear behavior after that point, unlike the IM7-8552 laminates whose bearing stress-displacement relations are approximately linear up to first load drop, at approximately $80 \%$ of the maximum bearing stress. This nonlinear behavior exhibited by the thin-ply laminates was also observed in the compression tests discussed previously, and it may be related with the onset and propagation of subcritical damage such as matrix cracking and fiber kinking before final failure. These early failure mechanisms may be promoted by the low thickness of these laminates $(2.0 \mathrm{~mm}$ and $1.3 \mathrm{~mm}$ for lay-up 1 and lay-up 2, respectively). For bearing stresses greater than the initial peak bearing strength, subcritical damage mechanisms start to interact, resulting in permanent damage such as through-the-thickness shear cracks, whose propagation, after this point, conducts to the sudden load drops shown in figure 26(a).

A linear behavior can be observed in the bearing stress-longitudinal strain relations shown in figure 26(b) for both thin-ply laminates, even during remote loading-unloading caused by damage evolution close to the hole. These results mean that the specimens' regions far from the bearing hole show a linear-elastic behavior, independently of the damage evolution in the vicinity of the hole.

Table 9 shows, for both thin-ply laminates and for the IM7-8552 laminate, the mean values of the normalized bearing strengths, defined as the normalized bearing stress at first load drop $\left(\bar{\sigma}_{N}^{b}=\left.\sigma_{N}^{b}\right|_{1 \text { st load drop }}\right)$, and the respective standard deviations. 
Observing the bolt-bearing test results (figure 26 and table 9), it can be seen that the mechanical response of the thin-ply laminates when subjected to bearing loads is superior to that exhibited by the IM7-8552 laminate. In fact, the normalized bearing strengths for lay-up 1 and lay-up 2 are respectively $2.8 \%$ and $19.6 \%$ greater than that of the IM7-8552 laminate. This improved bearing performance of the thin-ply laminates when compared to the IM7-8552 laminate may result from the ability of the thin-ply laminates to block onset and propagation of damage mechanisms such as delamination, fiber kinking, matrix cracking, and through-the-thickness shear cracking.

Note that, generally, there is also a size effect related with the bearing strength of composite laminates: the bearing strength increases with increasing laminate thickness [24]. Therefore, taking into account that the IM7-8552 laminate is thicker than both thin-ply laminates studied in this work, possibly, for the same thickness, the differences in these results would be even more pronounced. In addition, these NCF thin-ply laminates had lower volume fraction $\left(V_{f}\right)$ than the IM7-8552 laminate and, unlike the latter, they were not manufactured using autoclave/hotpress, but vacuum bagging. Although these results should be treated with caution, they clearly highlight a potential advantage of using thin-ply laminates in composite bolted joints.

\section{Conclusions}

The work presented in this paper demonstrates that thin-ply laminates loaded in tension exhibit an approximately linear behavior up to final failure, indicating that unrecoverable severe damage, such as extensive transverse cracking and delamination, are mitigated. This behavior is particularly evident in laminates with smaller relative ply orientations and without ply "blocking", which exhibited a brittle type of net-section failure mode, dominated by fiber breakage. This type of failure mode is a result of an improvement of delamination and transverse cracking resistance, conducting to stronger unnotched laminates and delaying first-ply-failure for the moment just before failure. However, this ability to suppress damage development before failure can ultimately result in a laminate with a marginally higher notch sensitivity.

The pull-out failure mode was observed in the thin-ply laminates with maximum relative ply orientations and ply "blocking". Although the development of a more extensive damaged zone resulted in laminates with lower plain strengths, such damage was able to redistribute stresses and decrease stress concentrations near the notches and open-holes, resulting in laminates with lower notch sensitivity. Still, delamination and transverse cracking were absent on the straight free-edges of these laminates, whereas edge cracking is typically observed using standard prepreg CFRP laminates.

No substantial differences were found either in the effects of hole size nor in the notch sensitivity of the thin-ply laminates when compared with other CFRP laminates made of standard prepregs with similar stacking configurations. However, it is important to mention that the thin-ply laminates have a lower fiber volume fraction $\left(V_{f}\right)$ than the CFRP laminates analysed for comparative purposes, and that, unlike the latter, they were not manufactured using autoclave/hotpress. This fact demonstrates the potential of using low-cost thin-ply laminates in lightweight load-carrying structures.

When subjected to compressive loads, the development of damage resulted in a nonlinear behavior. Although both thin-ply laminates exhibited a net-section failure mode, a brittle type of failure was observed in the unnotched laminate with minimum relative ply orientations. In the laminate with higher relative ply orientations and ply "blocking", failure was triggered by other damage 


\section{Acknowledgements}

The authors acknowledge Chomarat (Ardèche, France), Aldila (Poway, California USA), VX Aerospace (Leesburg, Virginia USA), and Prof. S.W. Tsai (Stanford University, USA) for providing the material used in the experimental program carried out in this work. The authors also acknowledge Dr. Peter Linde and Dr. Stephane Mahdi (Airbus) for the useful discussions. The second and third authors would like to acknowledge the support of the Fundação para a Ciência e a Tecnologia under the grant FCT-DFRH-SFRH-BPD-78104-2011 and the Ciencia2008 program, respectively. 


\section{References}

\section{References}

[1] Kawabe K, Matsuo T, Maekawa Z. New Technology for Opening Various Reinforcing Fiber Tows. J Soc Mat Sci Jpn 1998;47(7):727-734 (in Japanese).

[2] Sihn S, Kim RY, Kawabe K, Tsai SW. Experimental studies of thin-ply laminated composites. Compos Sci Technol 2007;67:996-1008.

[3] Tessitore N, Riccio A. A novel FEM model for biaxial non-crimp fabric composite materials under tension. Comput Struct 2006;84:1200-1207.

[4] Petriccione A, Annicchiarico D, Antonucci V, Giordano M, Riccio A, Scaramuzzino F. A stiffness volume averaging based approach to model non-crimp fabric reinforced composites. Compos Sci Technol 2012;72:360-369.

[5] Roure T, Sanial P. C-PLY ${ }^{\mathrm{TM}}$, a new structural approach to multiaxials in composites. JEC Composites Magazine 2011;68:53-54.

[6] Tsai SW, Nettles AT. Representative test data on bi-angle thin-ply NCF. JEC Composites Magazine 2011;68:62-63.

[7] Tsai SW, Papila M. Thin-ply NCF: design for deformation through anisotropy. JEC Composites Magazine 2011;68:66-67.

[8] Tsai SW, Papila M. Homogenization made easy with bi-angle thin-ply NCF. JEC Composites Magazine 2011;68:70-71.

[9] Tsai SW. Theory of Composites Design. Stanford: Stanford University, 2008.

[10] Skillen RS, Kelkar AD. Processing bi-angle non-crimp fabrics. JEC Composites Magazine 2011;68:64-65.

[11] GOM International AG. Bremgarterstrasse 89B, CH-8967 Widen, Switzerland.

[12] Xavier J, de Jesus AMP, Morais JJL, Pinto JMT. Stereovision measurements on evaluating the modulus of elasticity of wood by compression tests parallel to the grain. Constr Build Mater 2012;26(1):207-215.

[13] Standard test method for open-hole compressive strength of polymer matrix composite laminates, ASTM D 6484/D 6484M-09. American Society for Testing and Materials (ASTM). West Conshohocken, PA, USA.

[14] Camanho PP, Catalanotti G. On the relation between the mode I fracture toughness of a composite laminate and that of a $0^{\circ}$ ply: Analytical model and experimental validation. Eng Fract Mech 2011;78:2535-2546.

[15] Whitney JM, Nuismer RJ. Stress fracture criteria for laminated composites containing stress concentrations. J Compos Mater 1974;8:253-265. 
[16] Standard test method for bearing response of polymer matrix composite laminates, ASTM D 5961/D 5961M-01. American Society for Testing and Materials (ASTM). West Conshohocken, PA, USA.

[17] Camanho PP, Dávila CG, Pinho ST, Iannucci L, Robinson P. Prediction of in situ strengths and matrix cracking in composites under transverse tension and in-plane shear. Compos Part A-Appl S 2006;37:165-176.

[18] Erçin GH, Camanho PP, Xavier J, Catalanotti G, Mahdi S, Linde P. Size effects on the tensile and compressive failure of notched composite laminates. Compos Struct 2013;96:736-744.

[19] Camanho PP, Erçin GH, Catalanotti G, Mahdi S, Linde P. A finite fracture mechanics model for the prediction of the open-hole strength of composite laminates. Compos Part A-Appl S 2012;43:1219-1225.

[20] Green BG, Wisnom MR, Hallett SR. An experimental investigation into the tensile strength scaling of notched composites. Compos Part A-Appl S 2007;38:867-878.

[21] Tan SC. Stress concentrations in laminated composites. Technomic, 2004

[22] Tsai SW, Ha S, Tay TE, Miyano Y, Sihn S. Strength \& Life of Composites. In: Tsai SW, editor. U.S.A. Aeronautics \& Astronautics, Stanford University, 2008.

[23] Camanho PP, Lambert M. A design methodology for mechanically fastened joints in laminated composite materials. Compos Sci Technol 2006;66:3004-3020.

[24] Collings TA. Experimentally Determined Strength of Mechanically Fastened Joints. In: Matthews FL, editor. Joining Fiber Reinforced Plastics. London: Elsevier Applied Science, 1987. p.9-63. 


\section{List of Figures}

$1 \quad$ Unnotched test results. . . . . . . . . . . . . . . . . . . . . . 20

2 Representative unnotched tension specimens after testing. . . . . . . . . . . . . . 21

3 Representative unnotched compression specimens after testing. . . . . . . . . . . . 22

4 Surface longitudinal strain fields at the maximum load for the thin-ply unnotched specimens loaded in tension. The loading direction is oriented horizontally. . . . . . . 23

5 Center-notched tension test results. . . . . . . . . . . . . . . . . 24

6 Center-notched compression test results. . . . . . . . . . . . . . . 25

$7 \quad$ Notched region of a tensile center-notched specimen just before final failure. $\quad \ldots . .26$

8 Representative center-notched tension specimens after testing. . . . . . . . . . . 27

9 Representative center-notched compression specimens after testing. . . . . . . . . . 28

10 Surface longitudinal strain fields at the maximum load for the thin-ply center-notched specimens loaded in tension. The loading direction is oriented horizontally. . . . . . . 29

11 Local stress-longitudinal strain relations for the thin-ply center-notched specimens loaded in tension. The loading direction is oriented horizontally. . . . . . . . . . . 30

12 Open-hole tension remote stress-displacement relations. . . . . . . . . . . . . . . . 31

13 Open-hole compression remote stress-displacement relations. . . . . . . . . . . . . 32

14 Open-hole tensile specimens before final fracture. . . . . . . . . . . . . . . . 33

15 Representative open-hole tension specimens after testing. . . . . . . . . . . . . 34

16 Remote stress-longitudinal strain relations for the open-hole compression specimens with the 2 mm diameter hole. . . . . . . . . . . . . . . . . . . 35

17 Representative open-hole compression specimens after testing. . . . . . . . . . . 36

18 Surface longitudinal strain fields at the maximum load for the thin-ply open-hole specimens with the $3 \mathrm{~mm}$ diameter hole loaded in tension. The loading direction is oriented horizontally. . . . . . . . . . . . . . . . .

19 Surface longitudinal strain fields at the maximum load for the thin-ply open-hole specimens with the $10 \mathrm{~mm}$ diameter hole loaded in tension. The loading direction is oriented horizontally. . . . . . . . . . . . . . . . . . . . . .

20 Surface longitudinal strain fields at the maximum load for the thin-ply open-hole specimens with the $7 \mathrm{~mm}$ diameter hole loaded in compression. The loading direction is oriented horizontally. . . . . . . . . . . . . . . . . . . . .

21 Local stress-longitudinal strain relations for the thin-ply open-hole specimens with the $3 \mathrm{~mm}$ diameter hole loaded in tension. The loading direction is oriented horizontally.

22 Local stress-longitudinal strain relations for the thin-ply open-hole specimens with the $10 \mathrm{~mm}$ diameter hole loaded in tension. The loading direction is oriented horizontally.

23 Identification of hole size effects in thin-ply laminates, and comparison with the $[90 / 45 / 0 /-45]_{3 \mathrm{~S}}(\mathrm{~L} 1)$ and $\left[90_{2} / 0_{2} / 45_{2} / 90_{2} / 0 / 45 /-45\right]_{\mathrm{S}}$ (L2) T800/M21 laminates. . 42

24 Analysis of the notch sensitivity of the thin-ply laminates. . . . . . . . . . . . 43

25 Failed bolt-bearing test specimens. . . . . . . . . . . . . . . . . . . 44

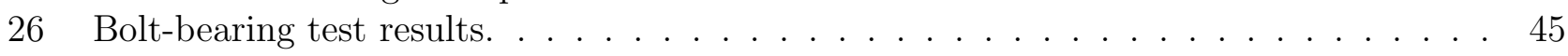




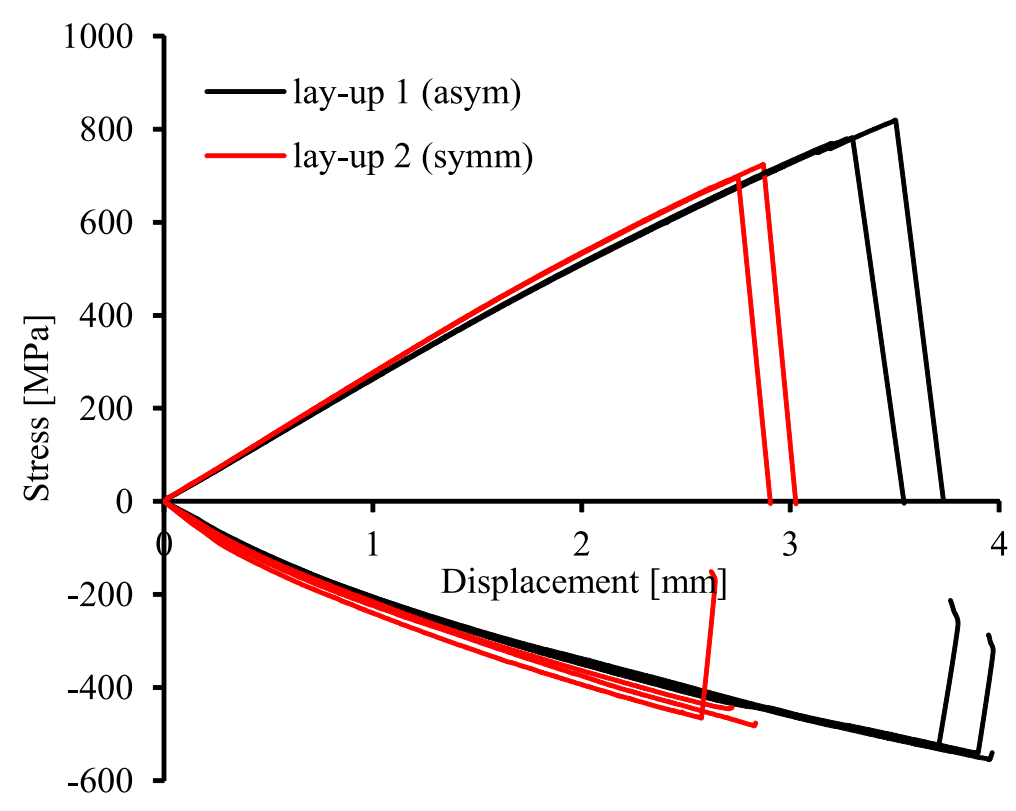

(a) Stress-displacement relations.

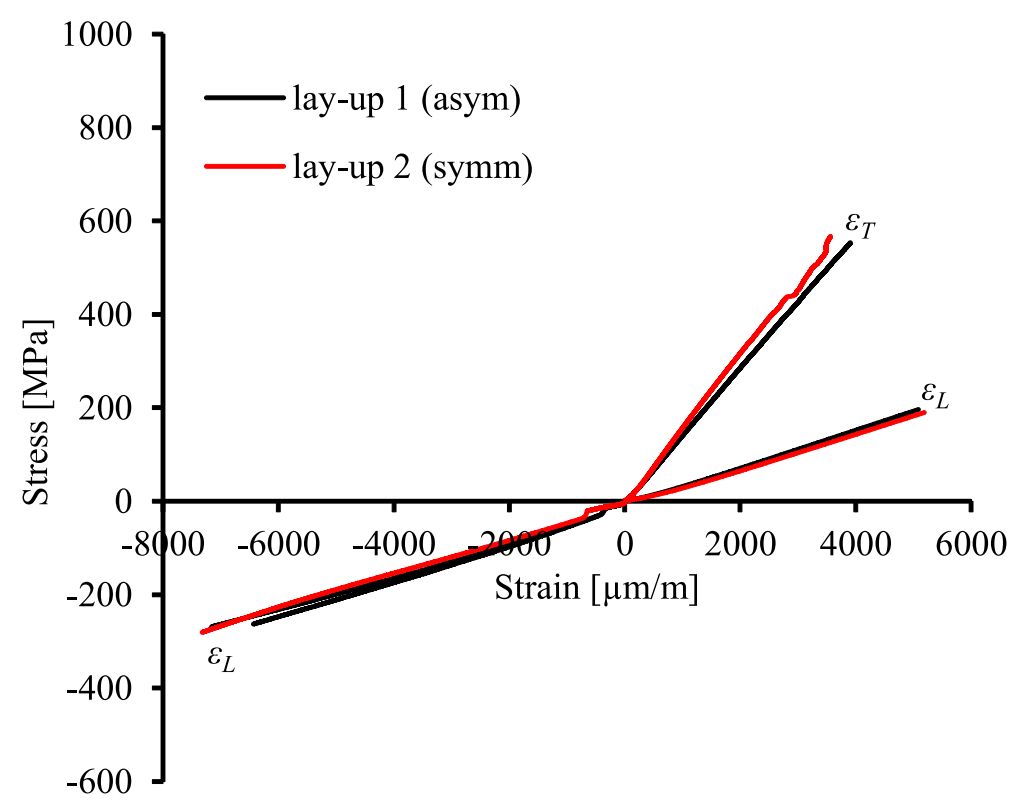

(b) Stress-strain relations.

Figure 1: Unnotched test results. 


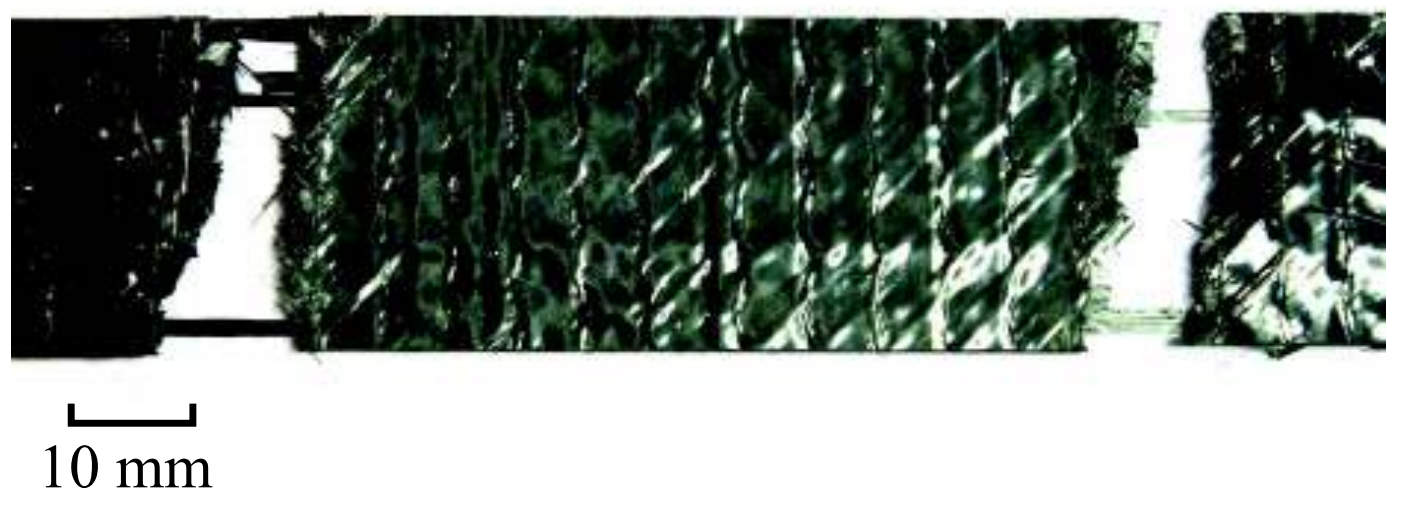

(a) Lay-up 1 (asymmetric) laminate.

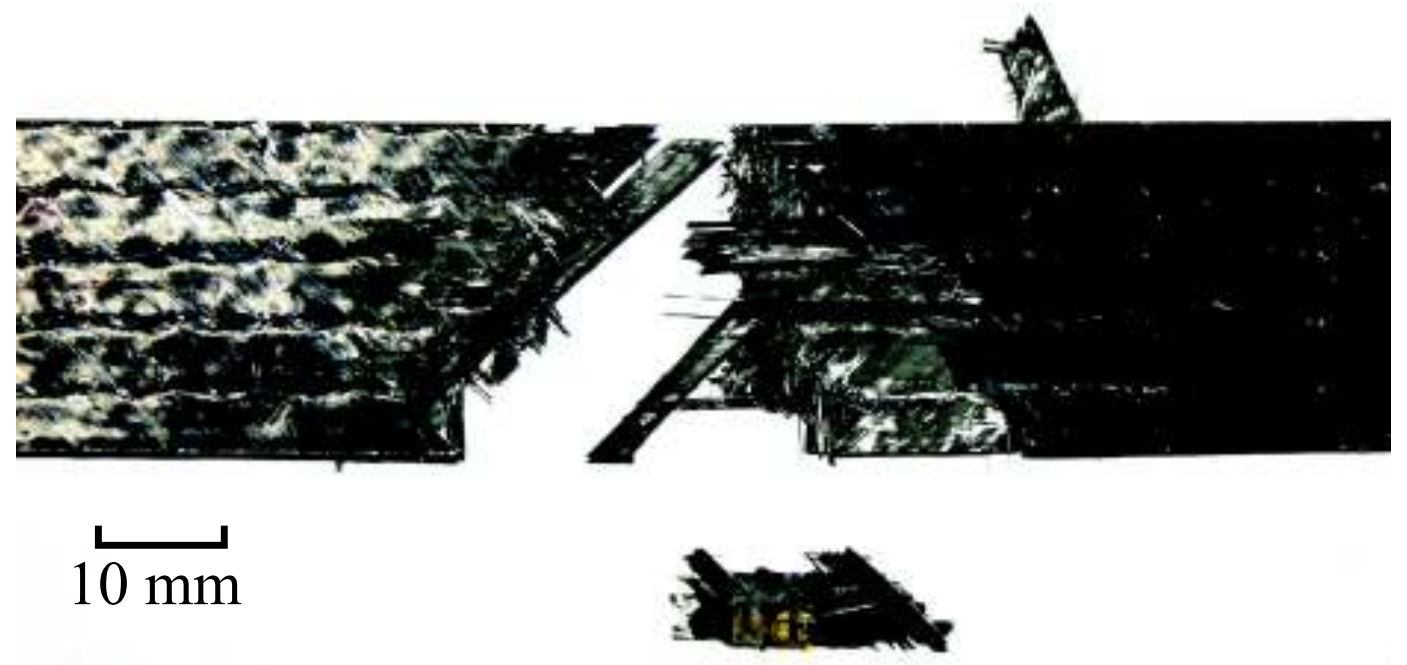

(b) Lay-up 2 (symmetric) laminate.

Figure 2: Representative unnotched tension specimens after testing. 


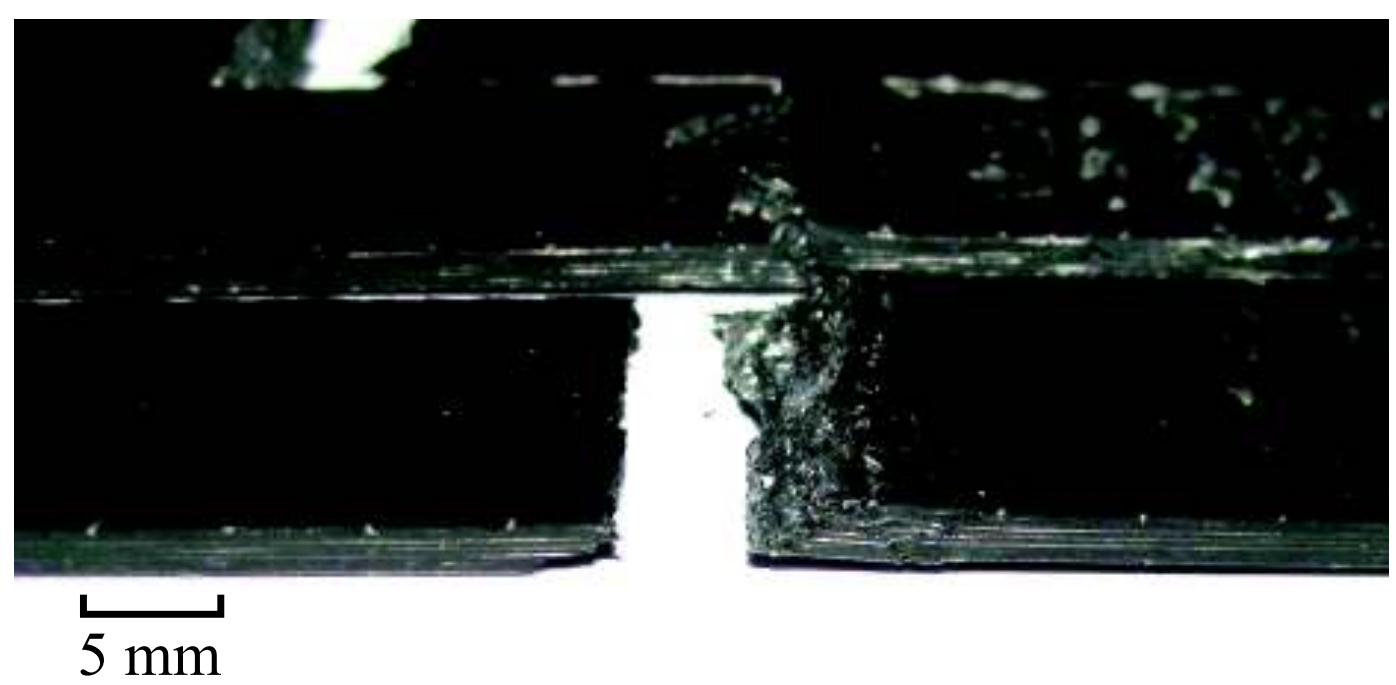

(a) Lay-up 1 (asymmetric) laminate.

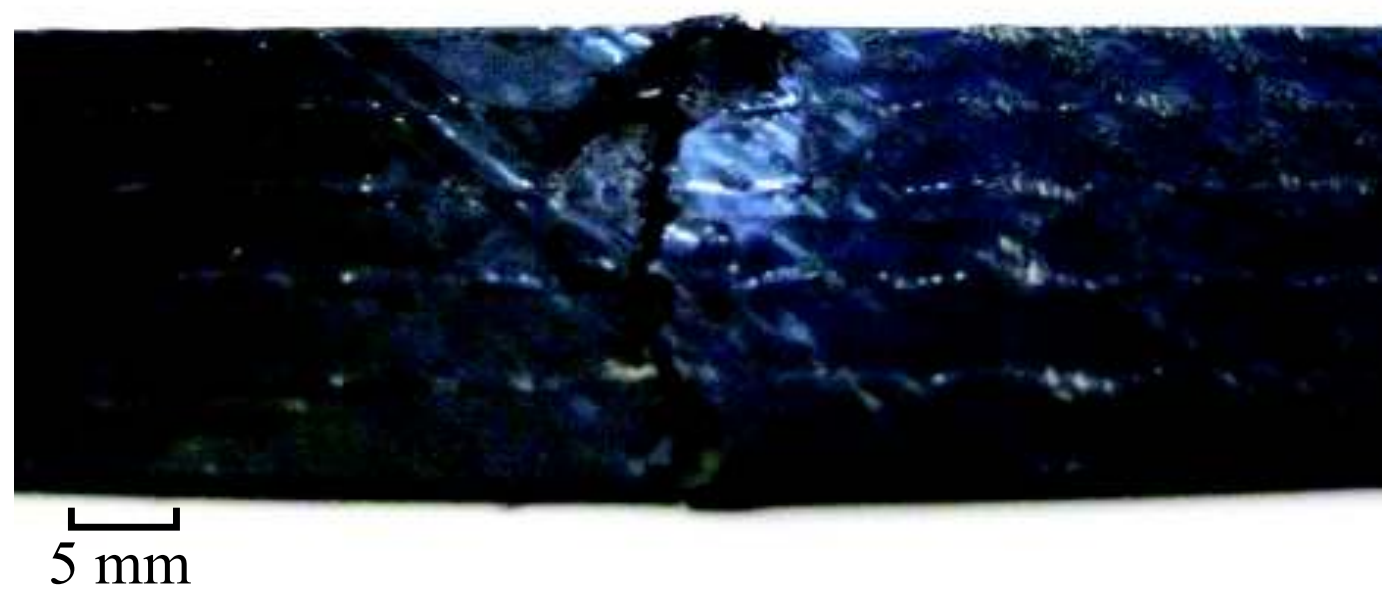

(b) Lay-up 2 (symmetric) laminate.

Figure 3: Representative unnotched compression specimens after testing. 

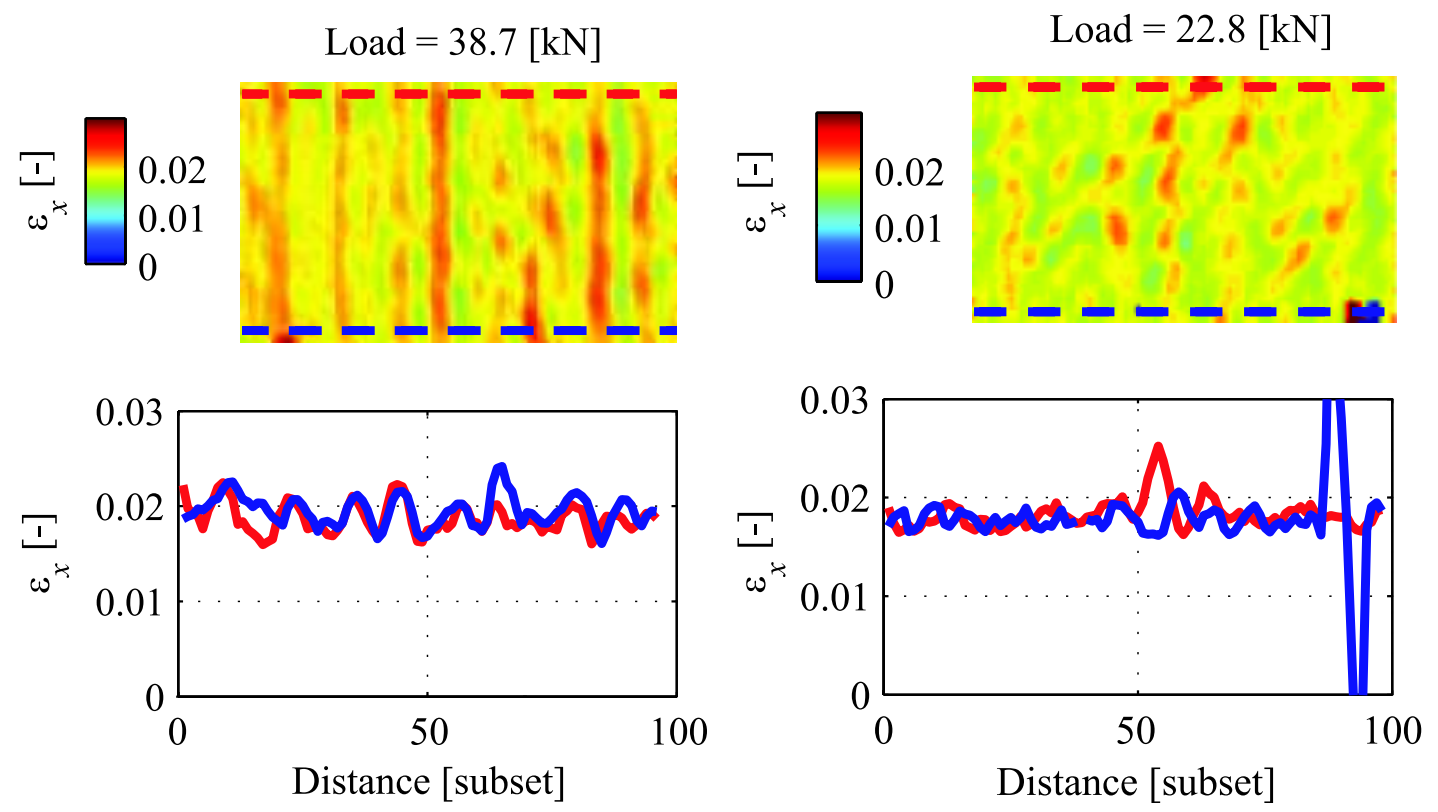

(a) Thin-ply lay-up 1 (asymmetric) laminate.

(b) Thin-ply lay-up 2 (symmetric) laminate.

Figure 4: Surface longitudinal strain fields at the maximum load for the thin-ply unnotched specimens loaded in tension. The loading direction is oriented horizontally. 


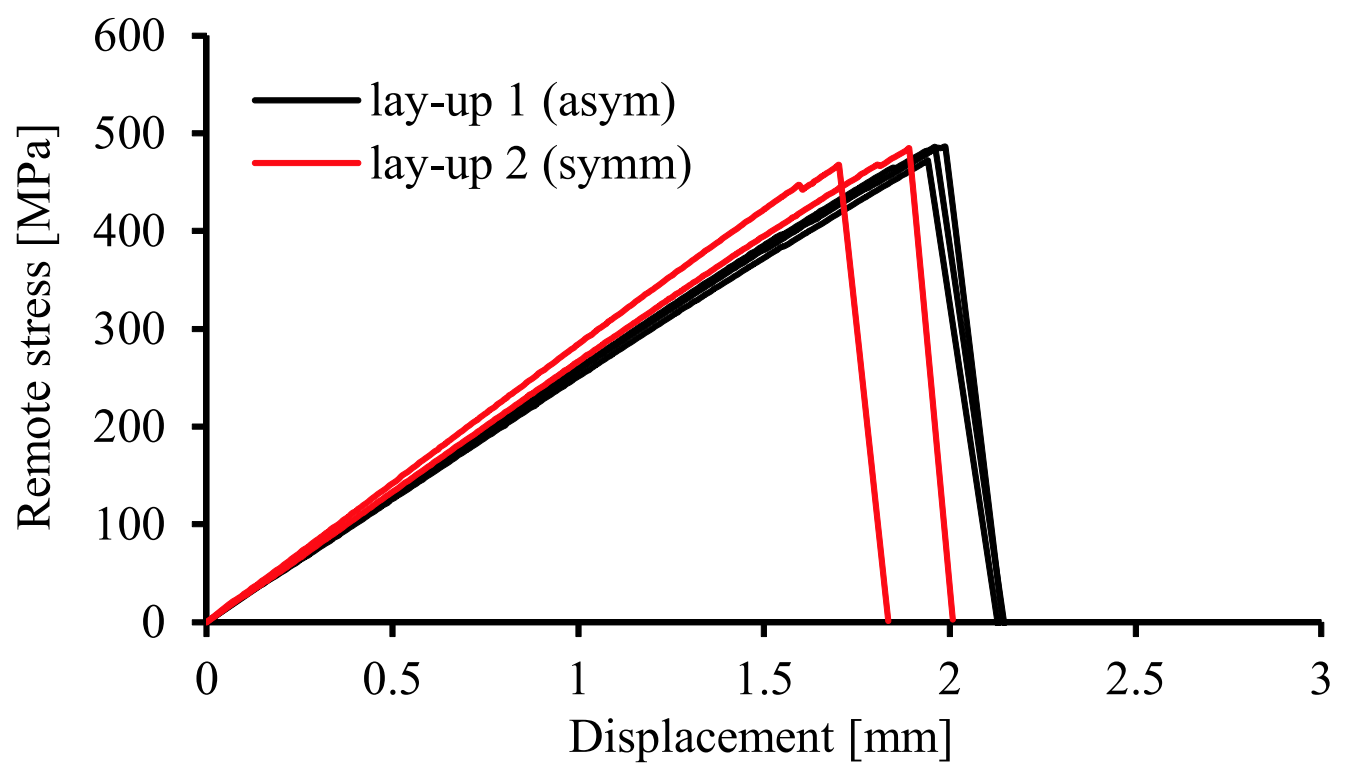

(a) Remote stress-displacement relations.

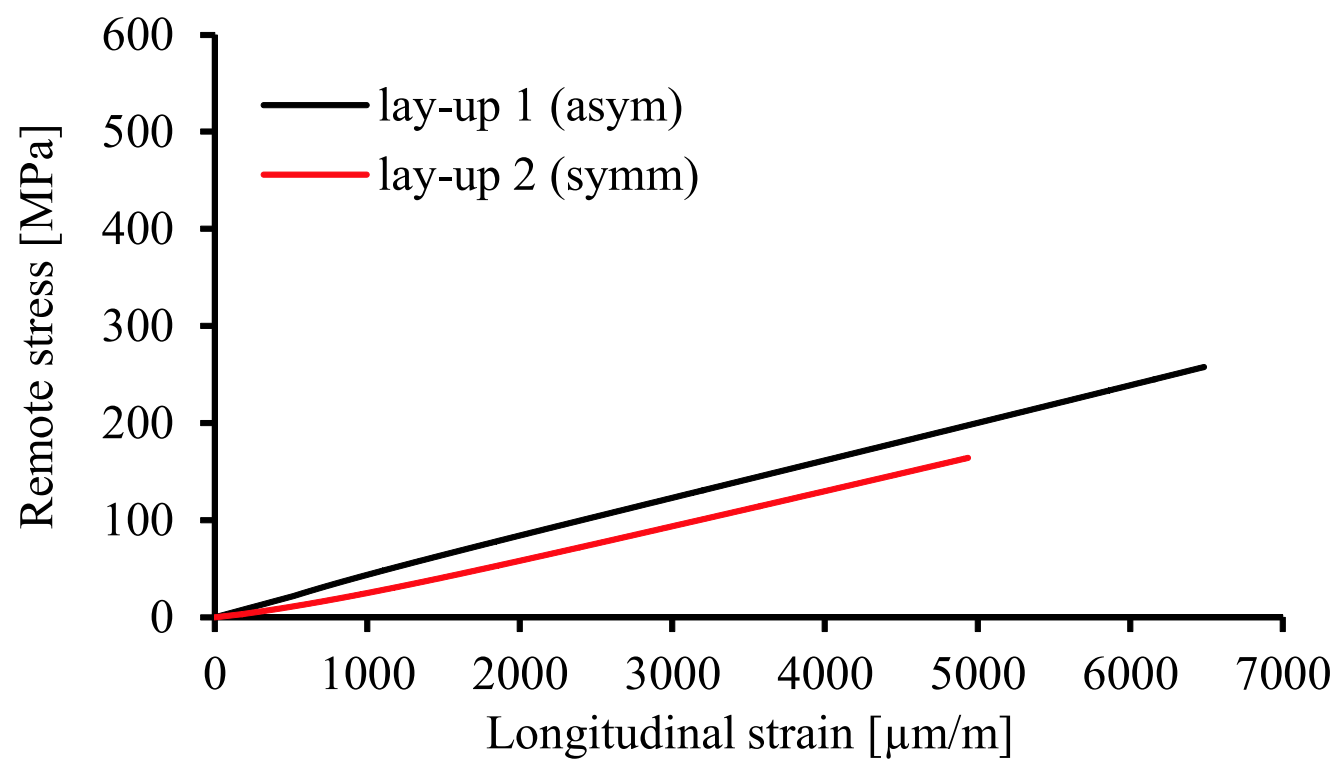

(b) Remote stress-longitudinal strain relations.

Figure 5: Center-notched tension test results. 


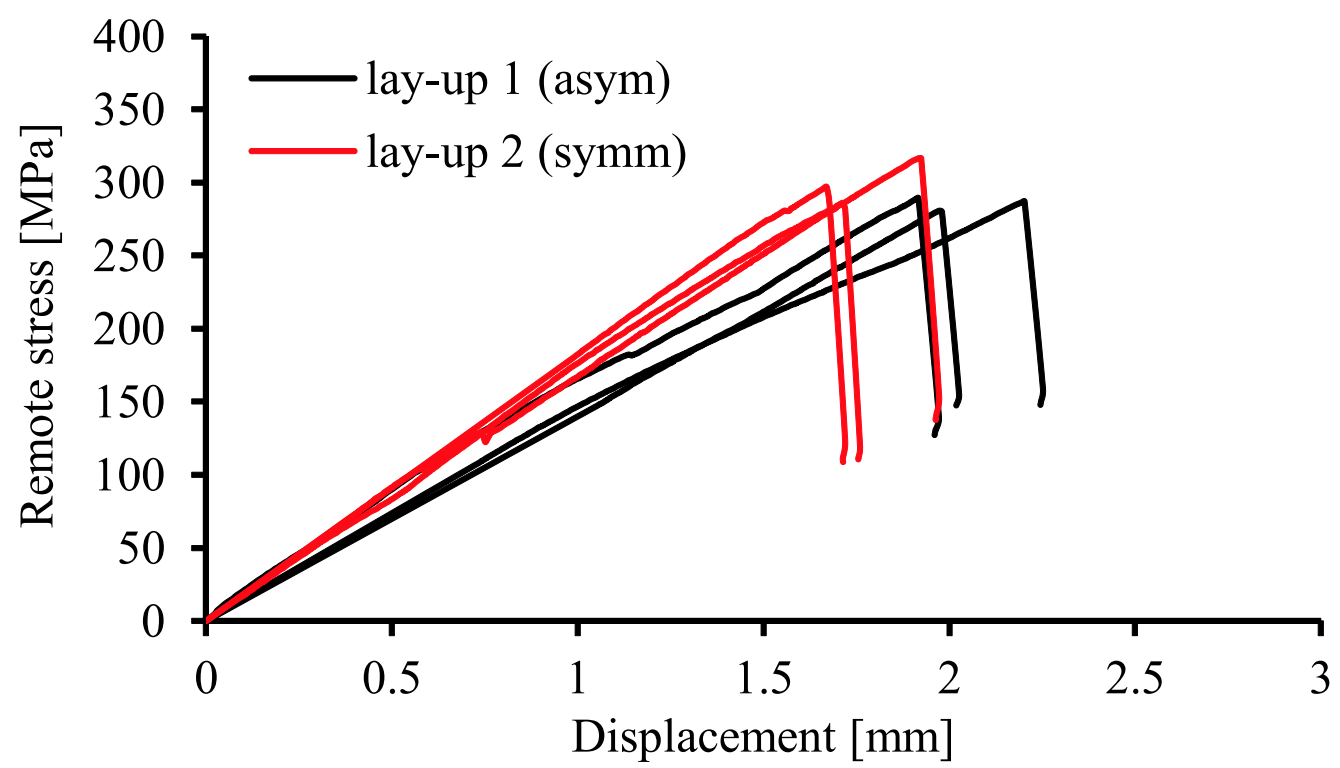

(a) Remote stress-displacement relations.

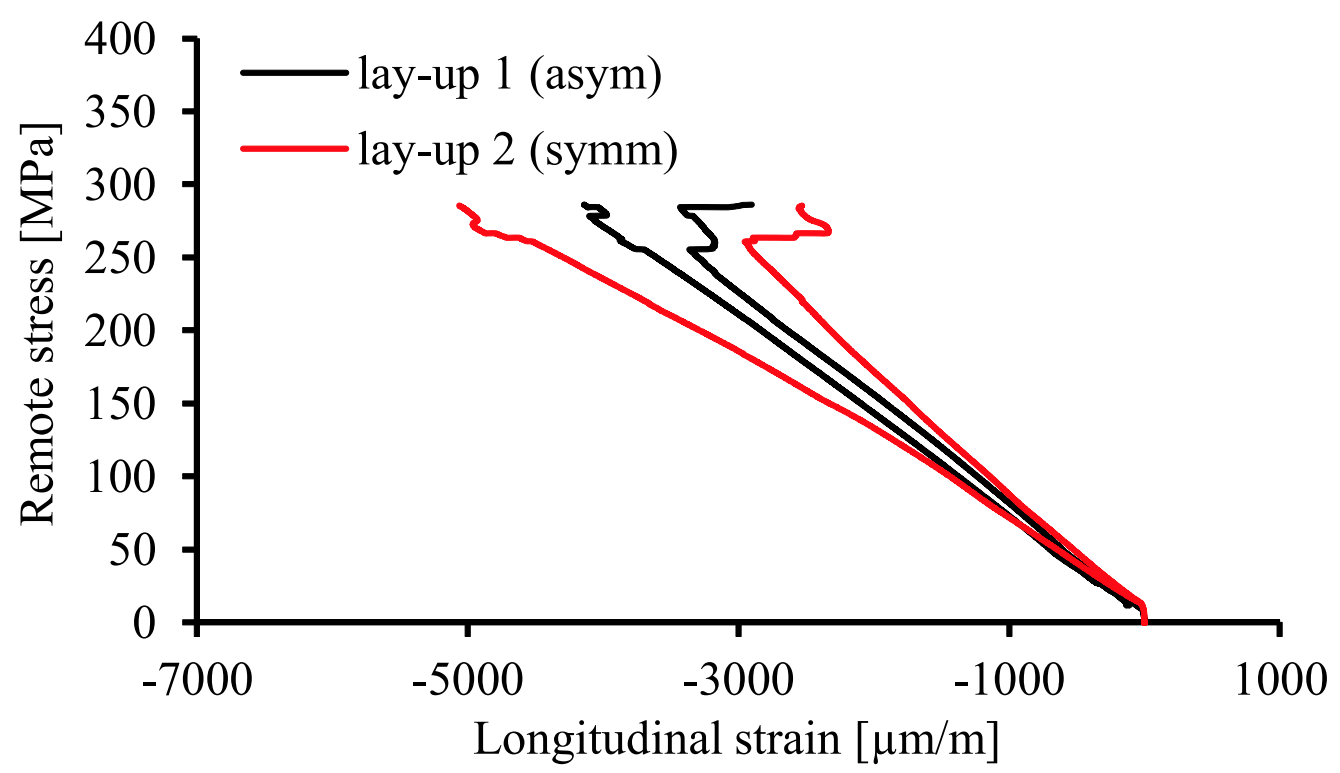

(b) Remote stress-longitudinal strain relations.

Figure 6: Center-notched compression test results. 


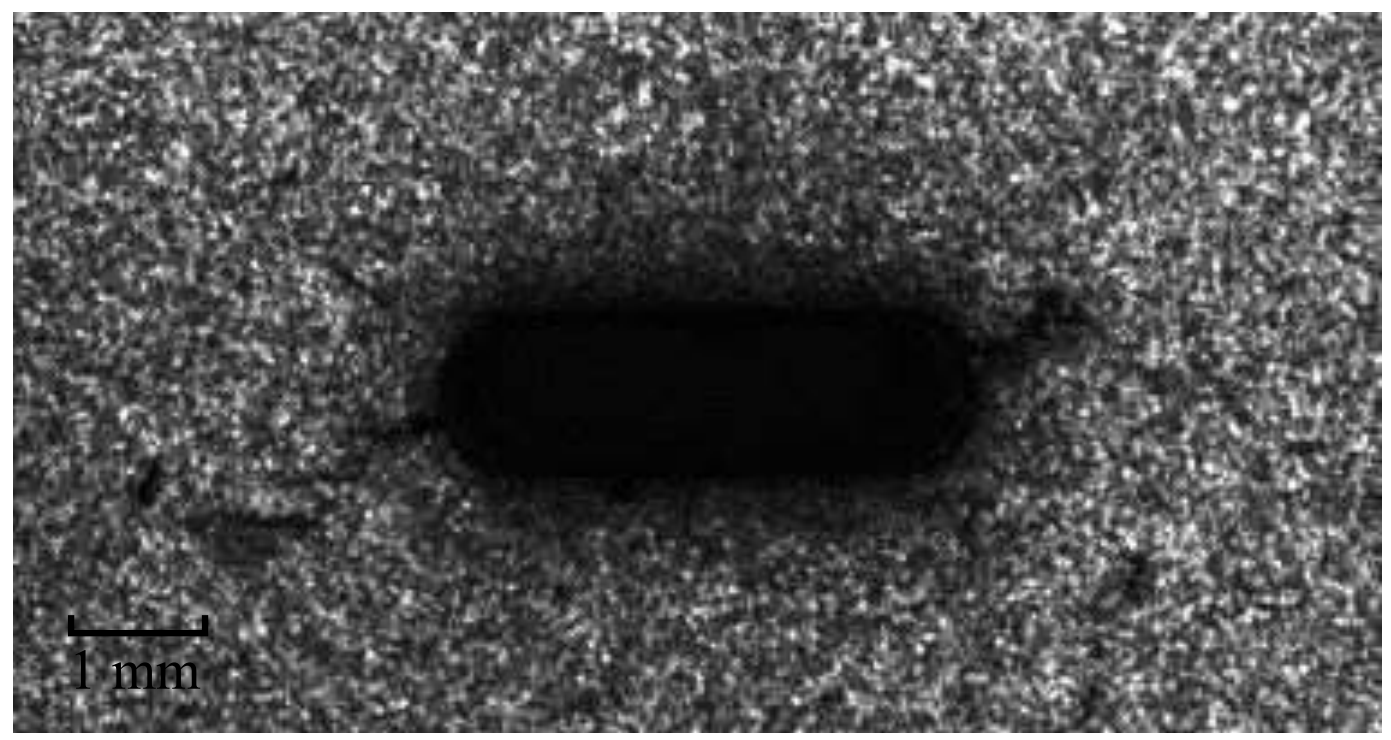

(a) Lay-up 1 (asymmetric) laminate.

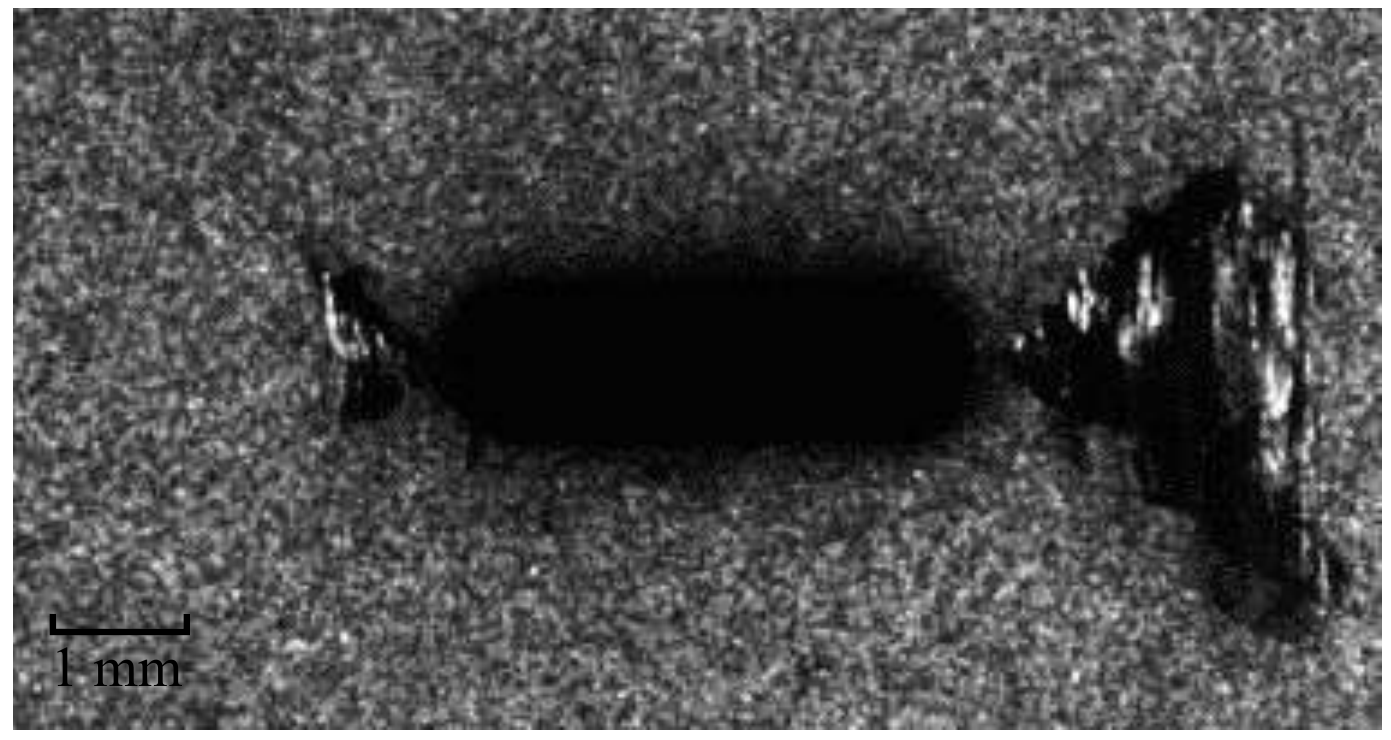

(b) Lay-up 2 (symmetric) laminate.

Figure 7: Notched region of a tensile center-notched specimen just before final failure. 

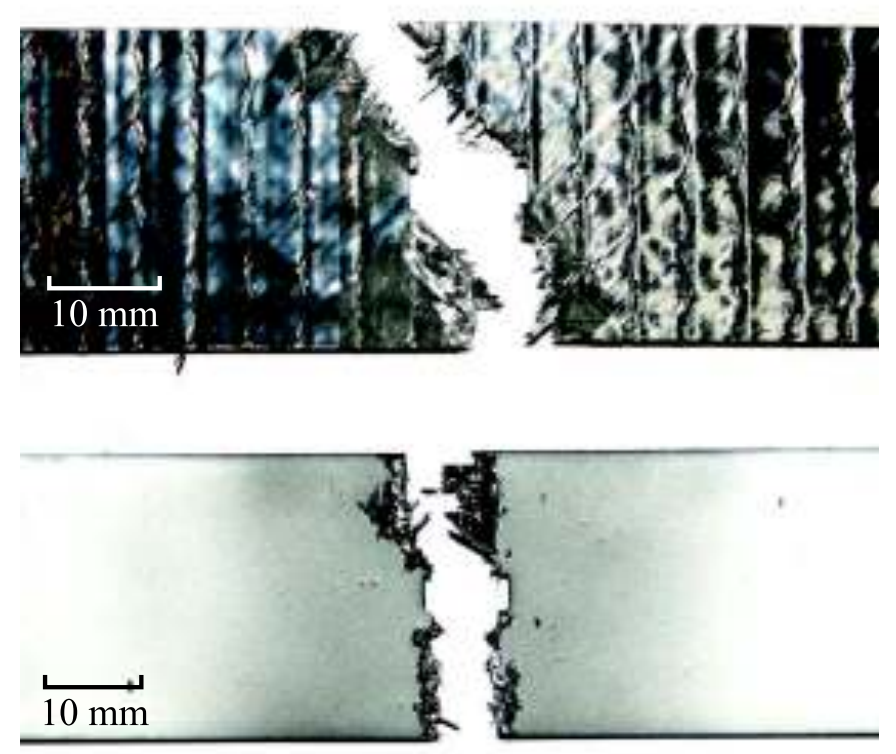

(a) Lay-up 1 (asymmetric) laminates.
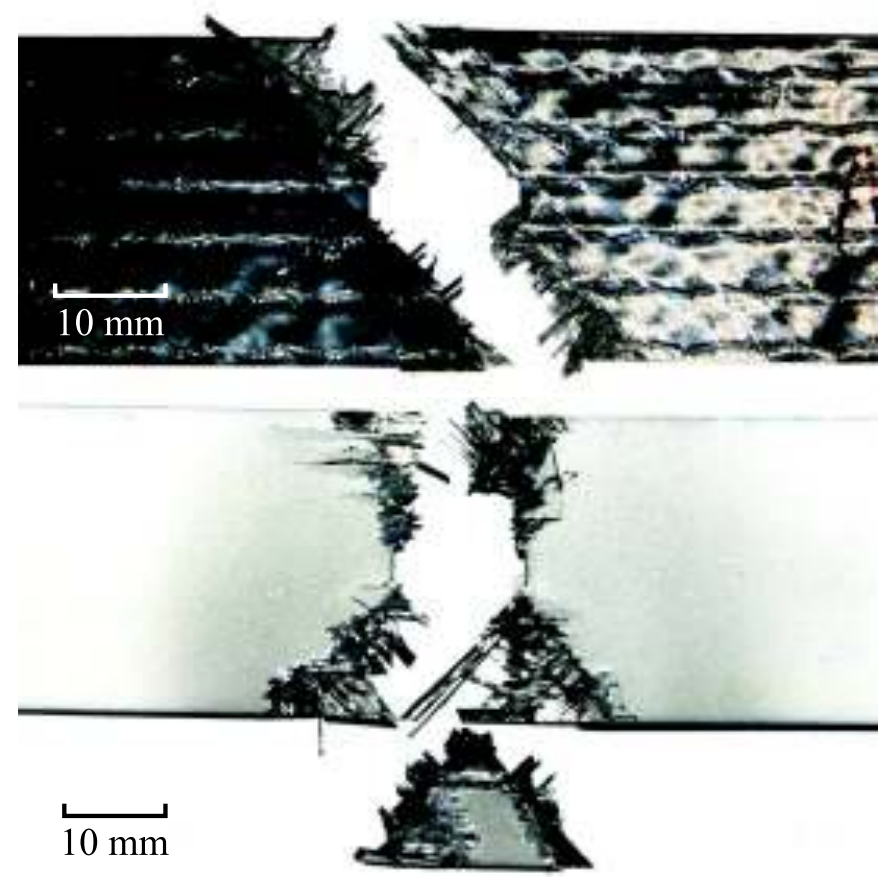

(b) Lay-up 2 (symmetric) laminates.

Figure 8: Representative center-notched tension specimens after testing. 


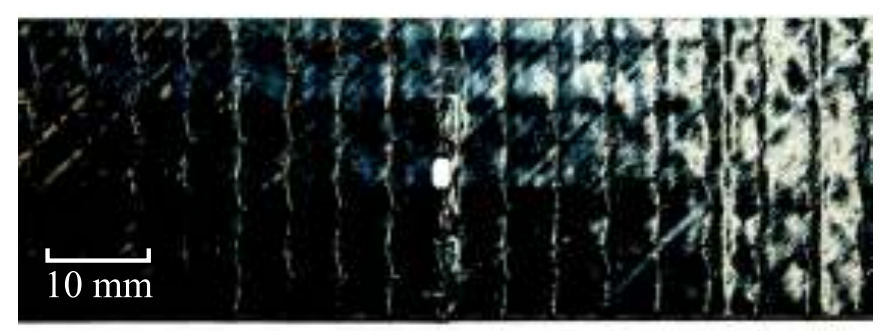

(a) Lay-up 1 (asymmetric) laminate.

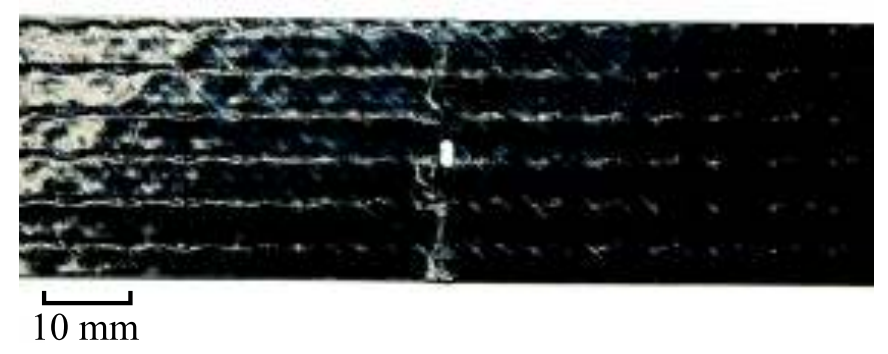

(b) Lay-up 2 (symmetric) laminate.

Figure 9: Representative center-notched compression specimens after testing. 


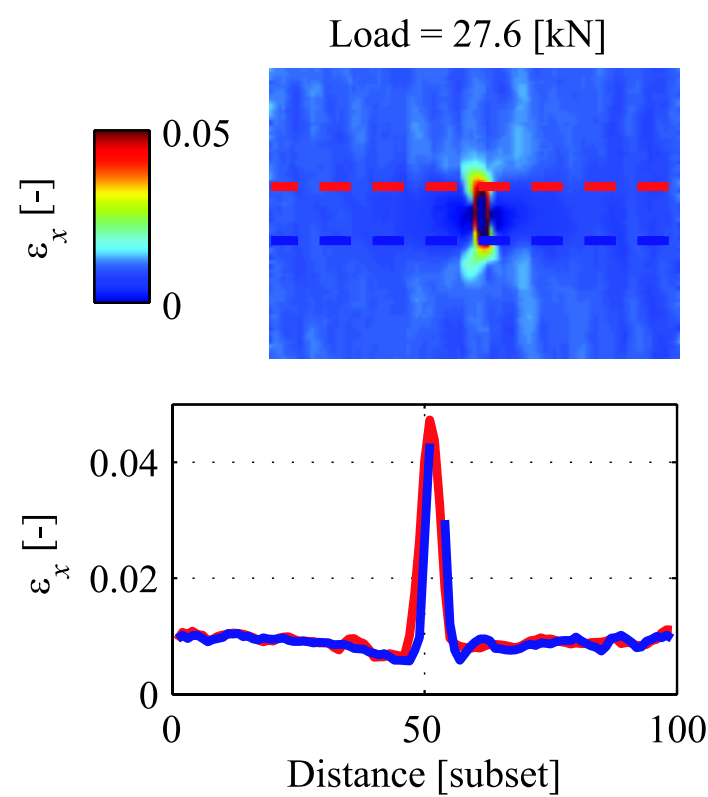

(a) Thin-ply lay-up 1 (asymmetric) laminate.
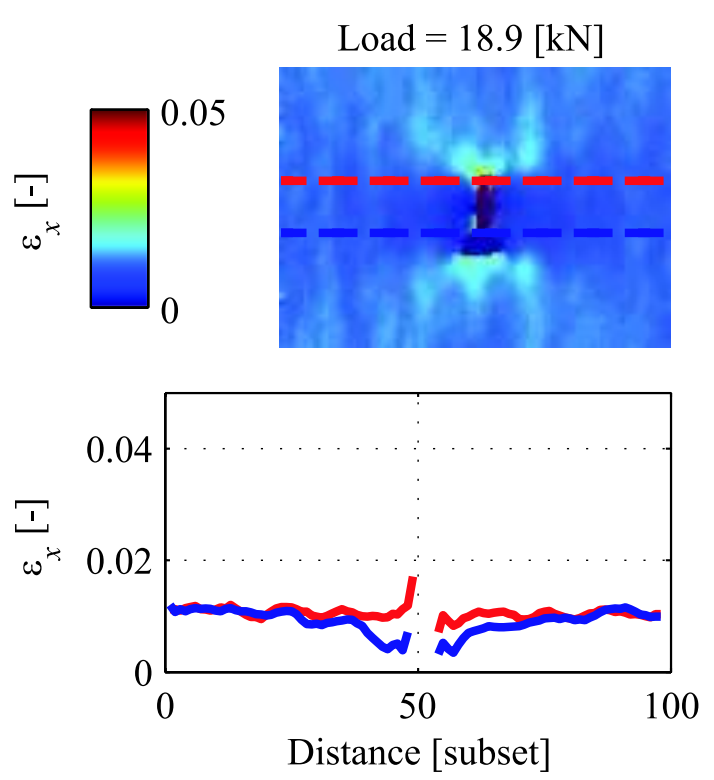

(b) Thin-ply lay-up 2 (symmetric) laminate.

Figure 10: Surface longitudinal strain fields at the maximum load for the thin-ply center-notched specimens loaded in tension. The loading direction is oriented horizontally. 

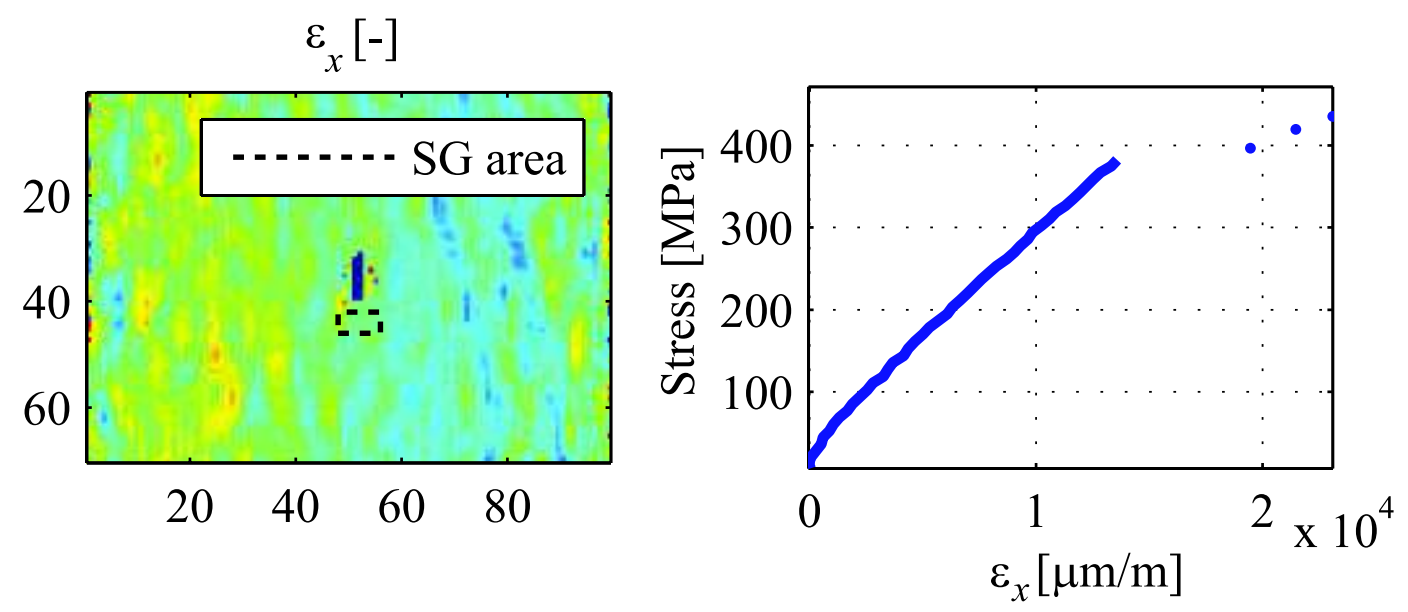

(a) Thin-ply lay-up 1 (asymmetric) laminate.
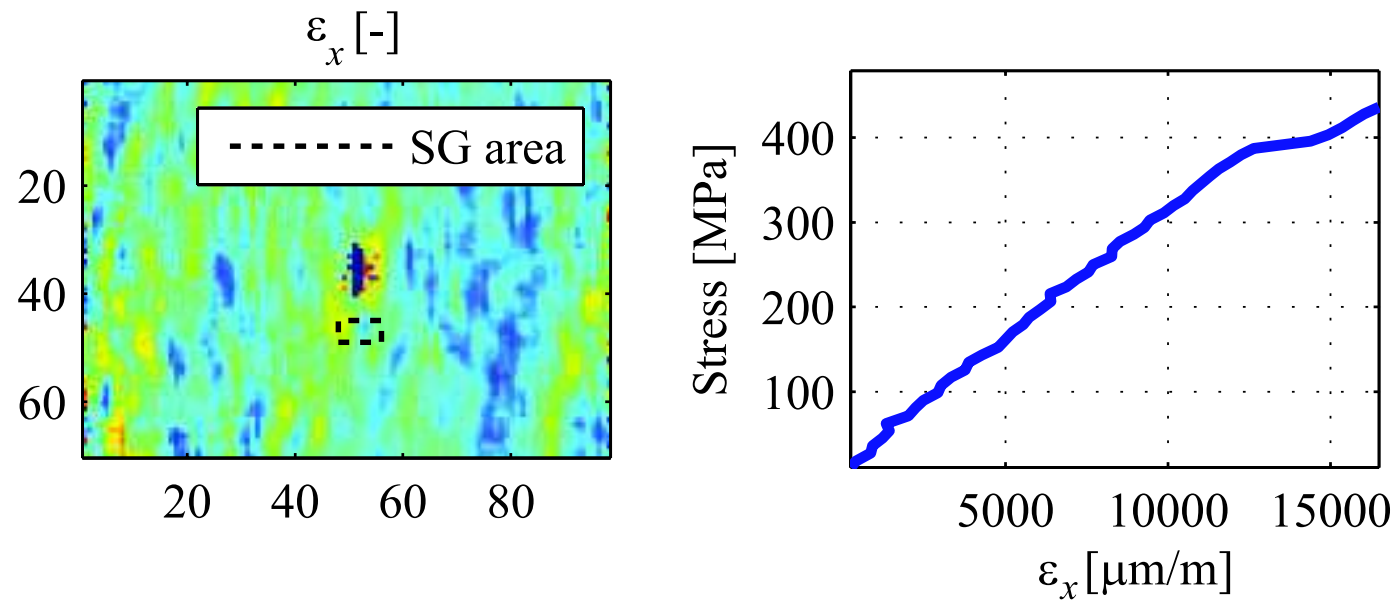

(b) Thin-ply lay-up 2 (symmetric) laminate.

Figure 11: Local stress-longitudinal strain relations for the thin-ply center-notched specimens loaded in tension. The loading direction is oriented horizontally. 


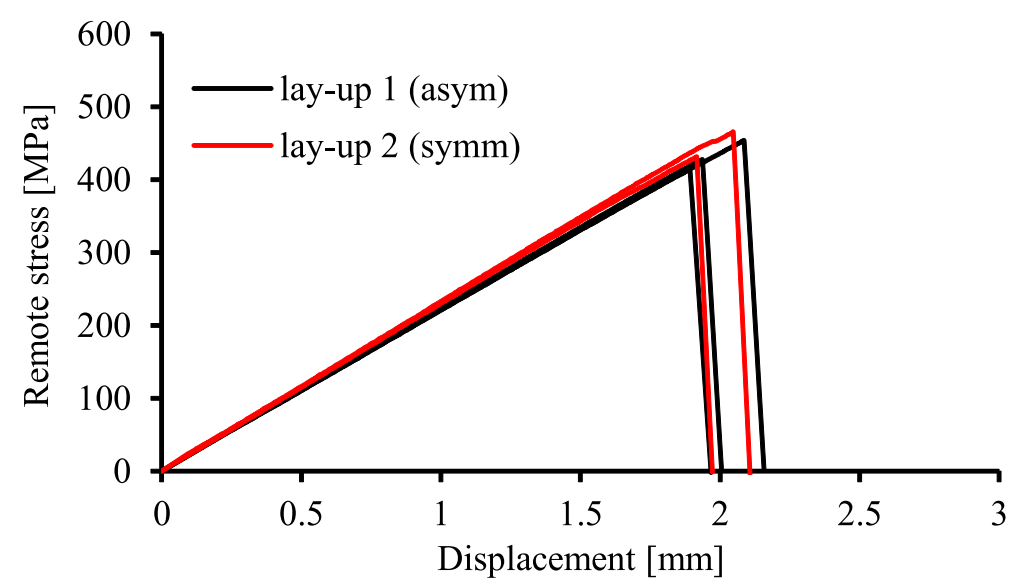

(a) Results for the specimens with the $3 \mathrm{~mm}$ diameter hole.

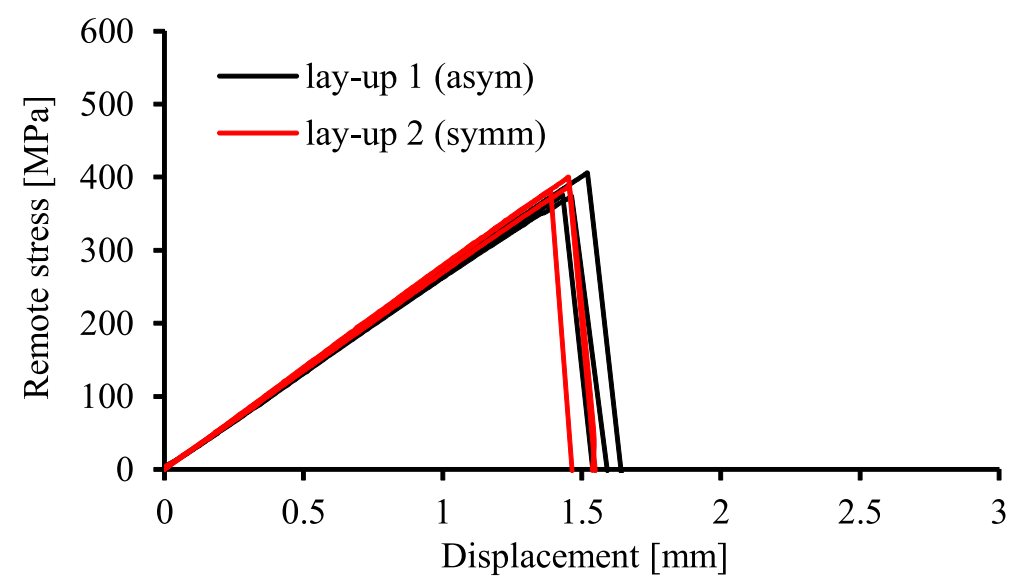

(b) Results for the specimens with the $6 \mathrm{~mm}$ diameter hole.

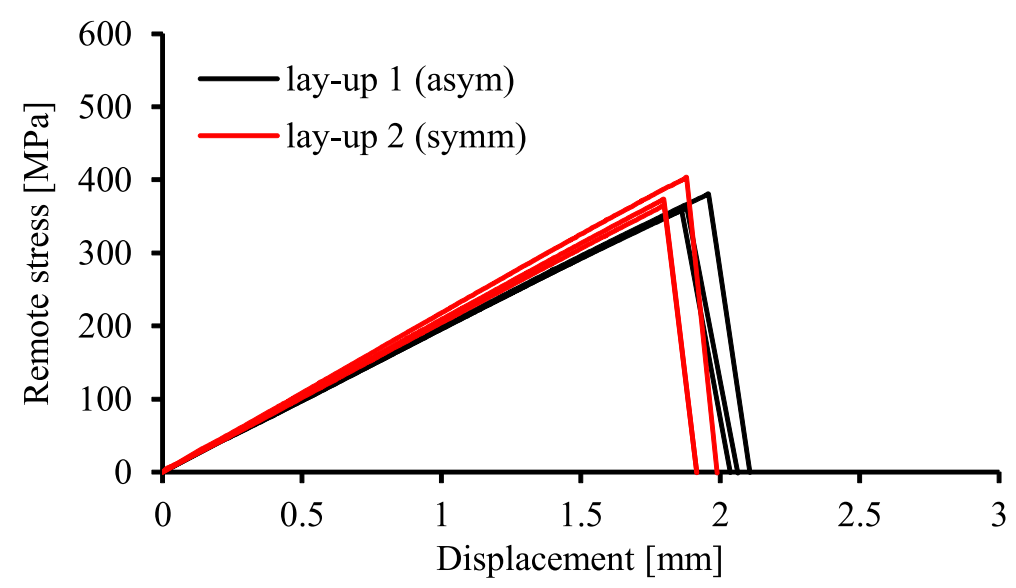

(c) Results for the specimens with the $10 \mathrm{~mm}$ diameter hole.

Figure 12: Open-hole tension remote stress-displacement relations. 


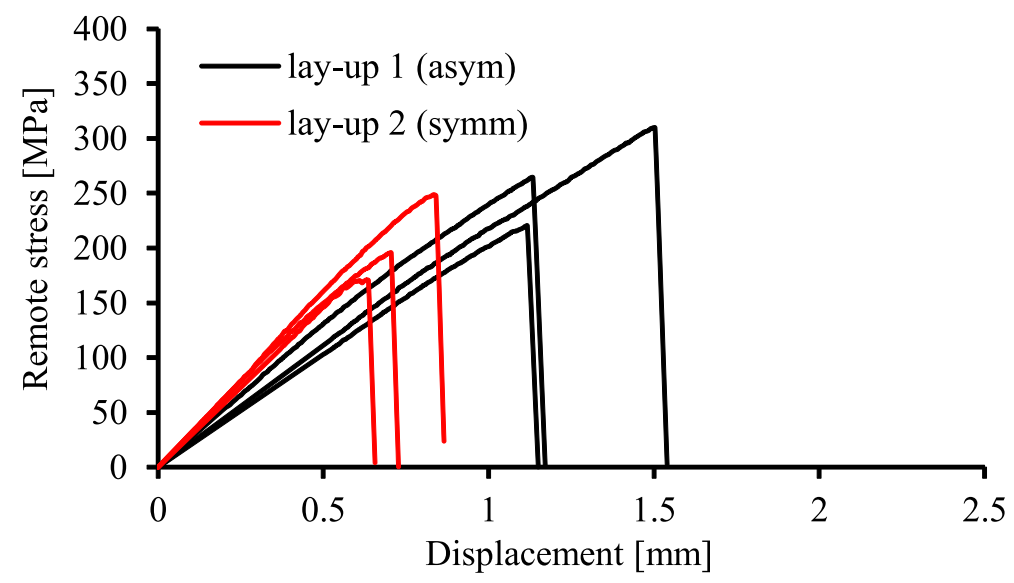

(a) Results for the specimens with the $2 \mathrm{~mm}$ diameter hole.

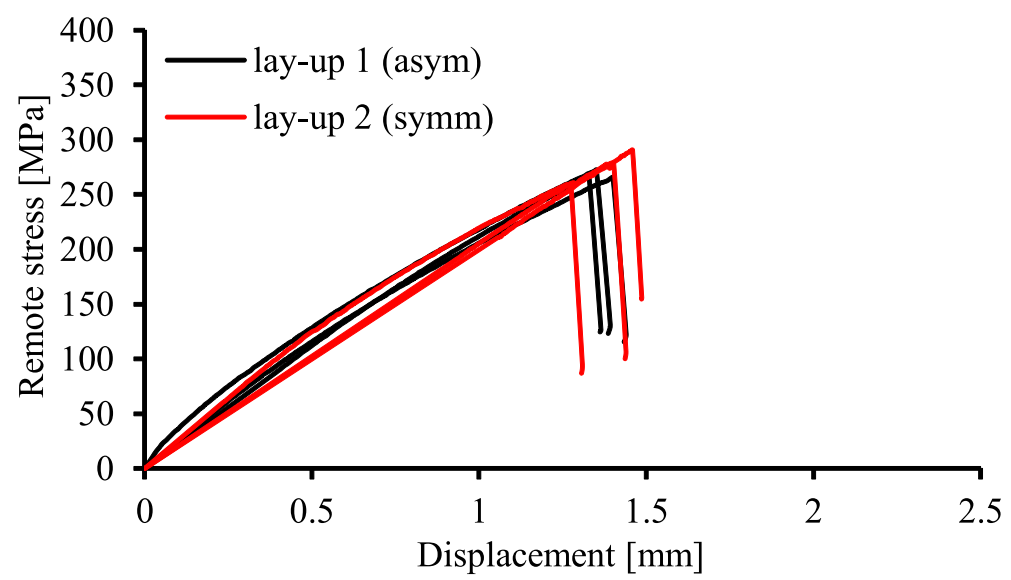

(b) Results for the specimens with the $5 \mathrm{~mm}$ diameter hole.

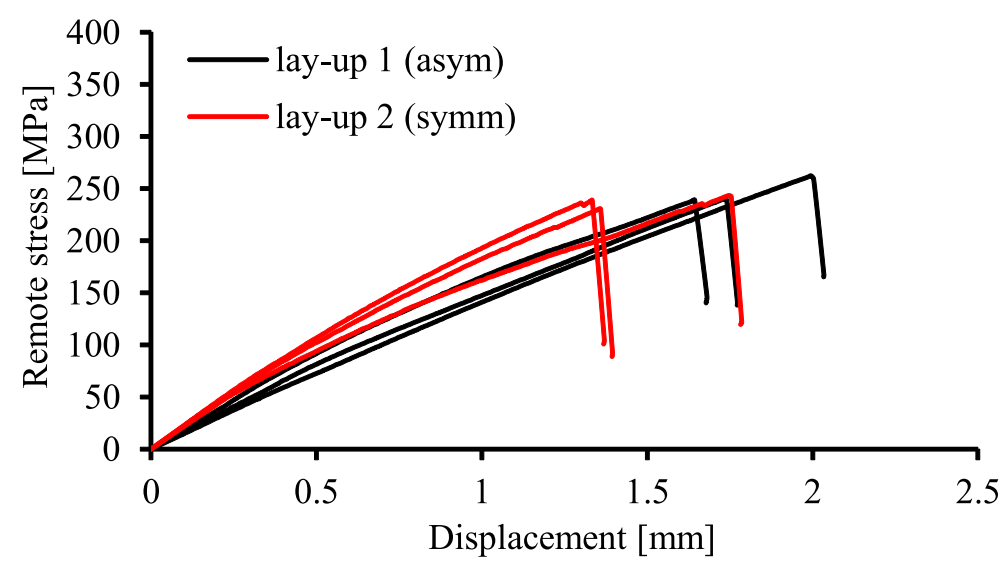

(c) Results for the specimens with the $7 \mathrm{~mm}$ diameter hole.

Figure 13: Open-hole compression remote stress-displacement relations. 


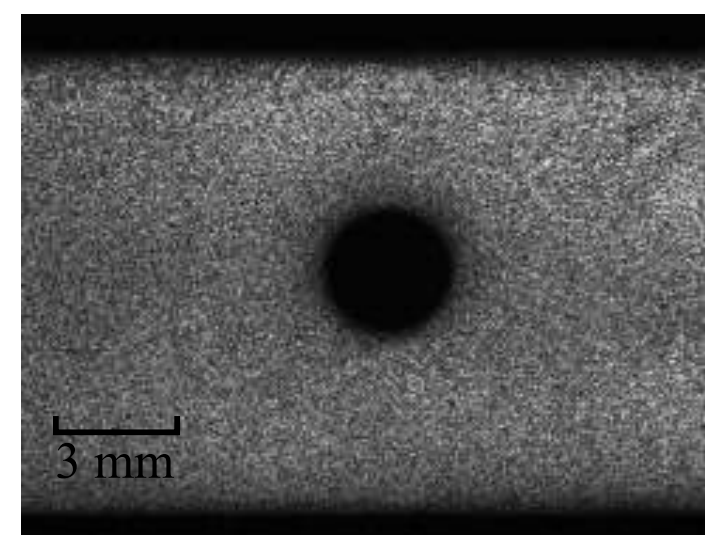

(a) Lay-up 1 (asymmetric) $-d=3 \mathrm{~mm}$.

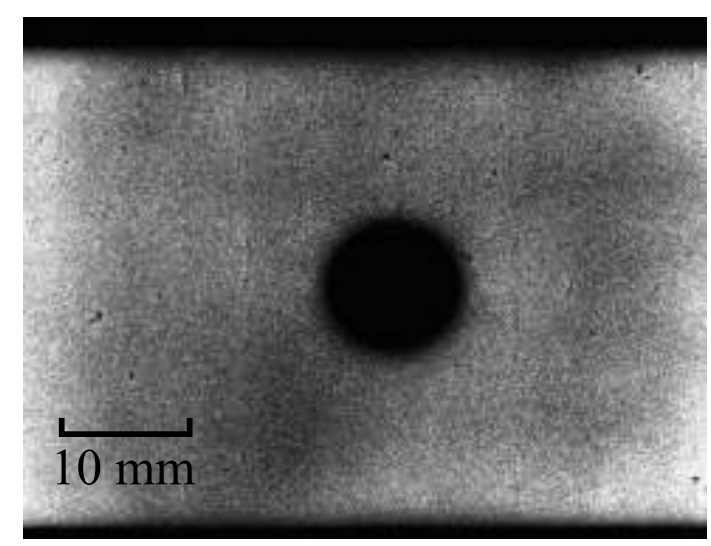

(c) Lay-up 1 (asymmetric) $-d=10 \mathrm{~mm}$.

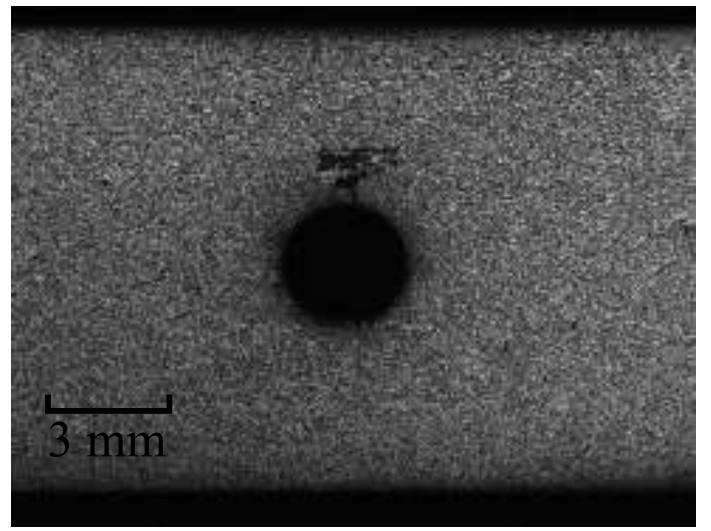

(b) Lay-up 2 (symmetric) $-d=3 \mathrm{~mm}$.

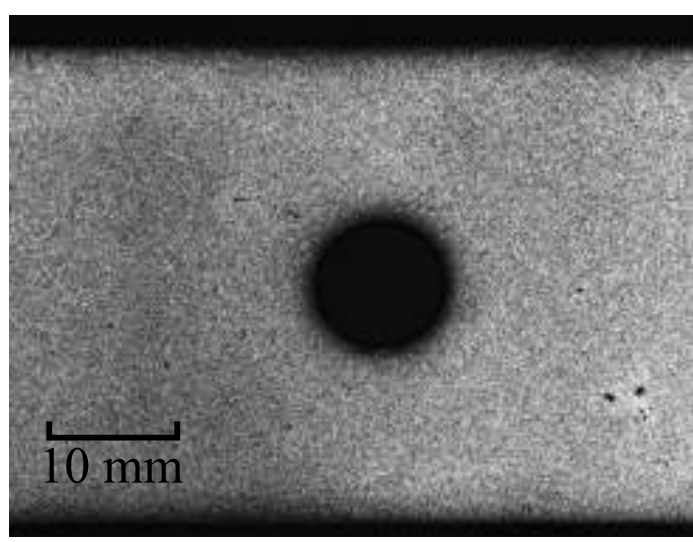

(d) Lay-up 2 (symmetric) $-d=10 \mathrm{~mm}$.

Figure 14: Open-hole tensile specimens before final fracture. 

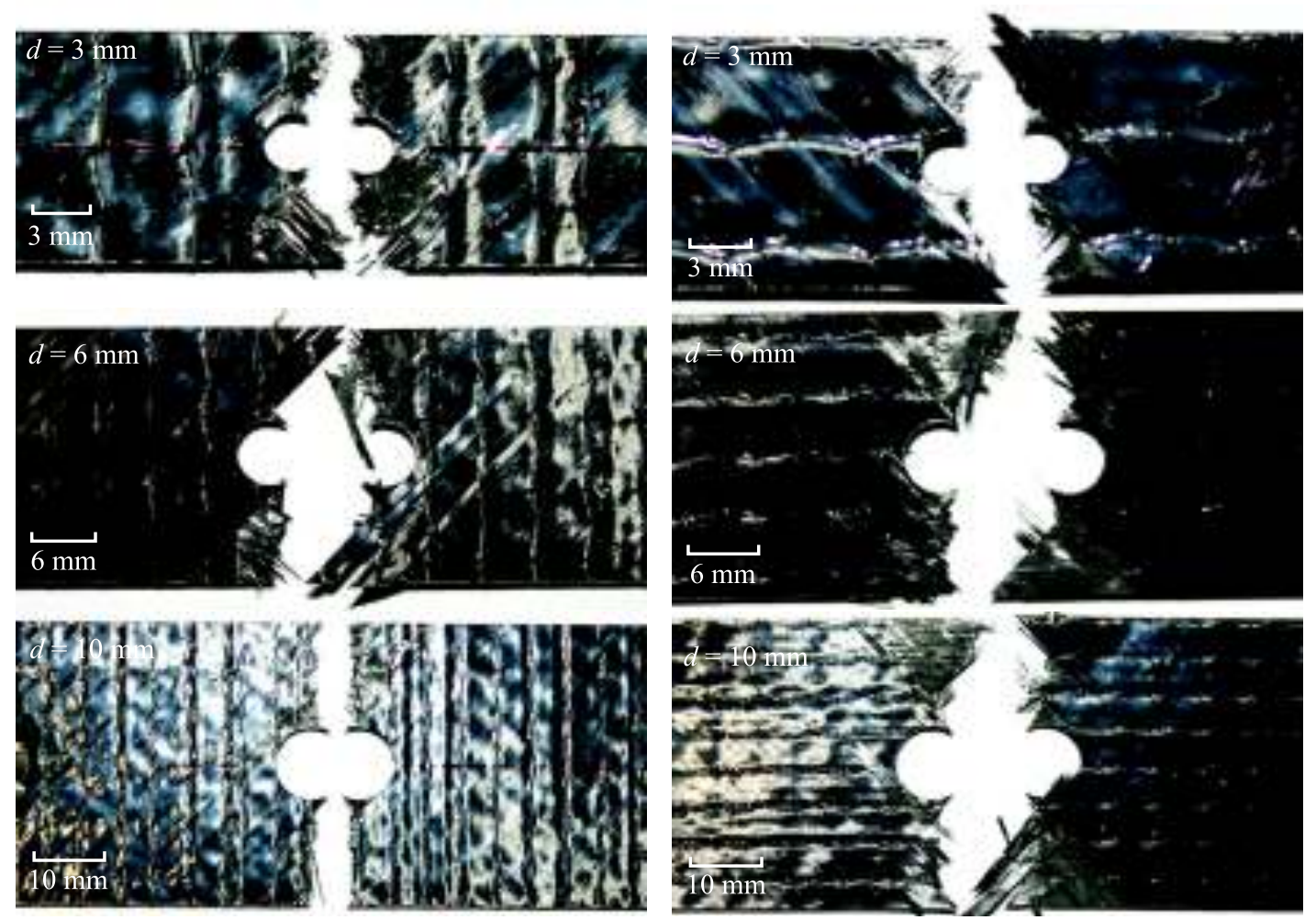

(a) Lay-up 1 (asymmetric) laminates.

(b) Lay-up 2 (symmetric) laminates.

Figure 15: Representative open-hole tension specimens after testing. 


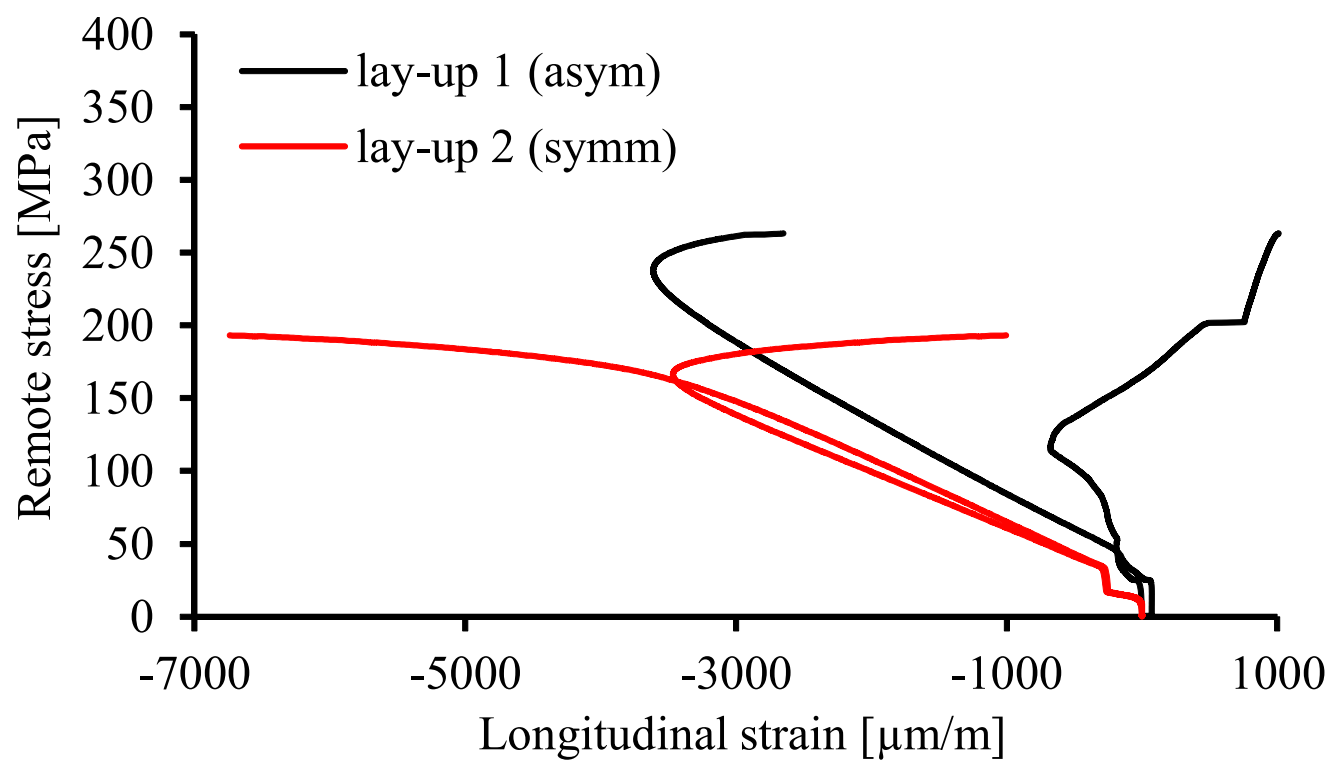

Figure 16: Remote stress-longitudinal strain relations for the open-hole compression specimens with the 2 mm diameter hole. 

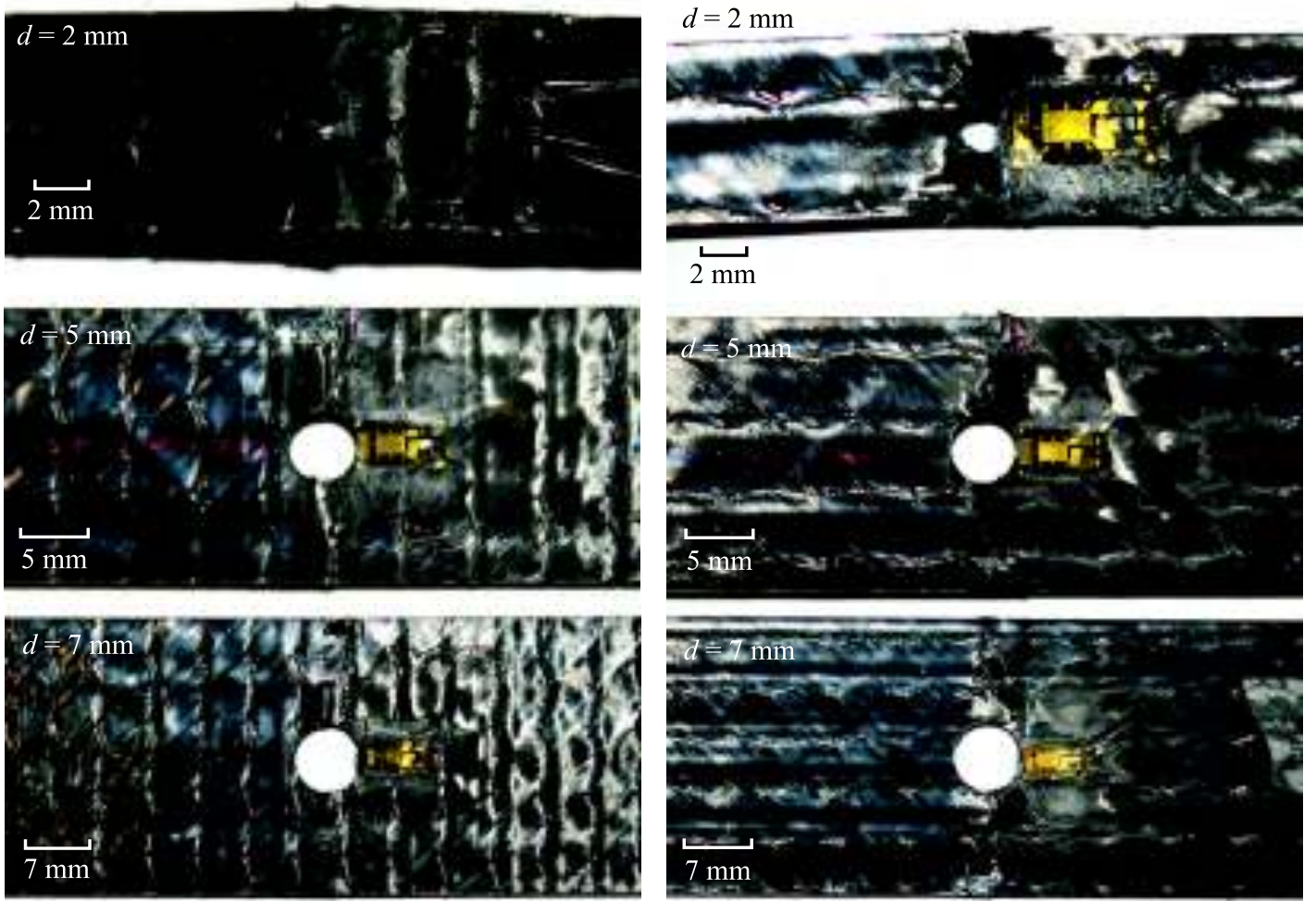

(a) Lay-up 1 (asymmetric) laminates.

(b) Lay-up 2 (symmetric) laminates.

Figure 17: Representative open-hole compression specimens after testing. 


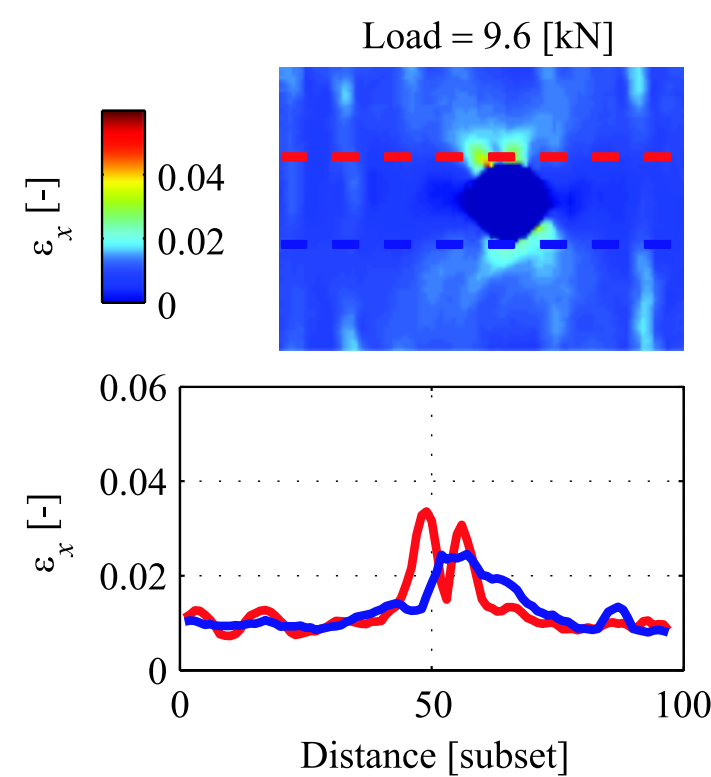

(a) Thin-ply lay-up 1 (asymmetric) laminate.
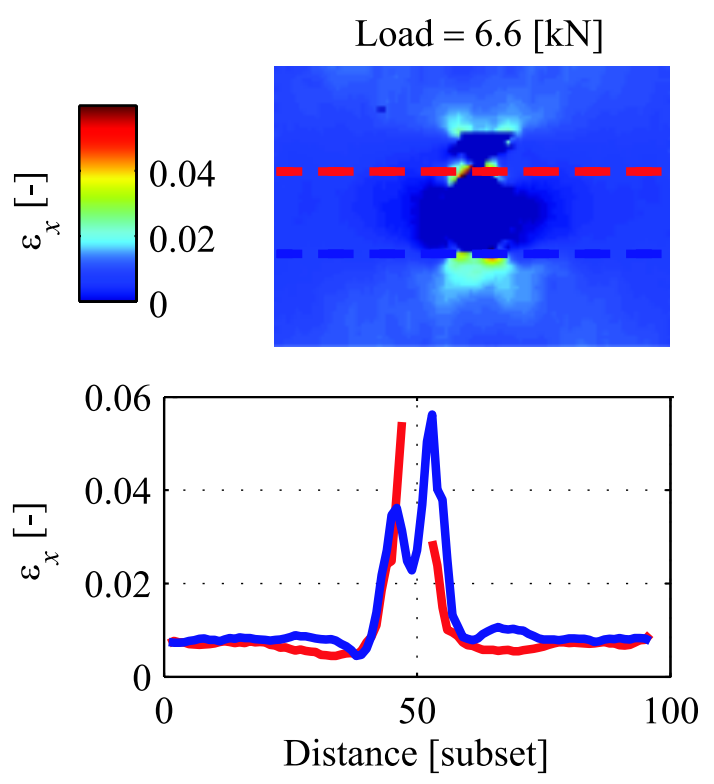

(b) Thin-ply lay-up 2 (symmetric) laminate.

Figure 18: Surface longitudinal strain fields at the maximum load for the thin-ply open-hole specimens with the $3 \mathrm{~mm}$ diameter hole loaded in tension. The loading direction is oriented horizontally. 

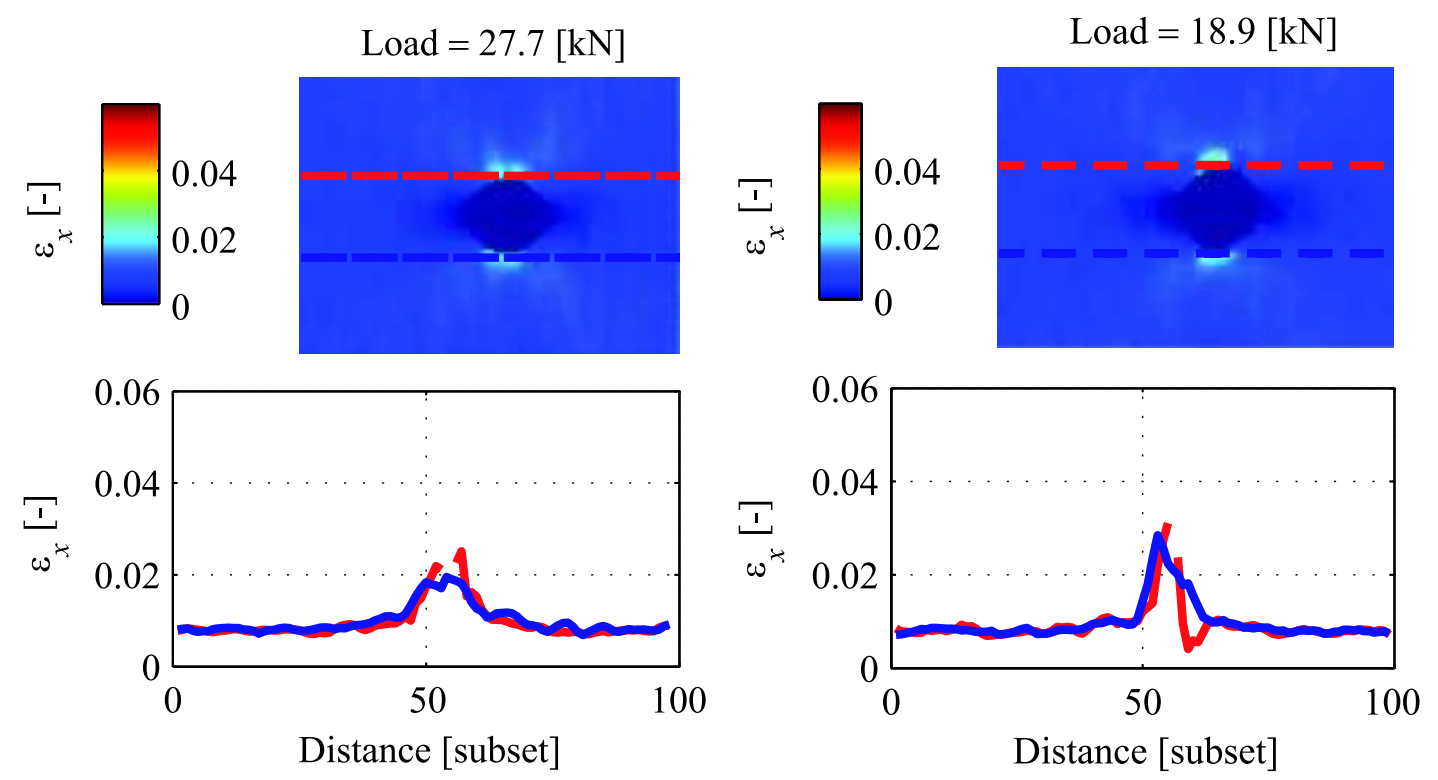

(a) Thin-ply lay-up 1 (asymmetric) laminate.

(b) Thin-ply lay-up 2 (symmetric) laminate.

Figure 19: Surface longitudinal strain fields at the maximum load for the thin-ply open-hole specimens with the $10 \mathrm{~mm}$ diameter hole loaded in tension. The loading direction is oriented horizontally. 


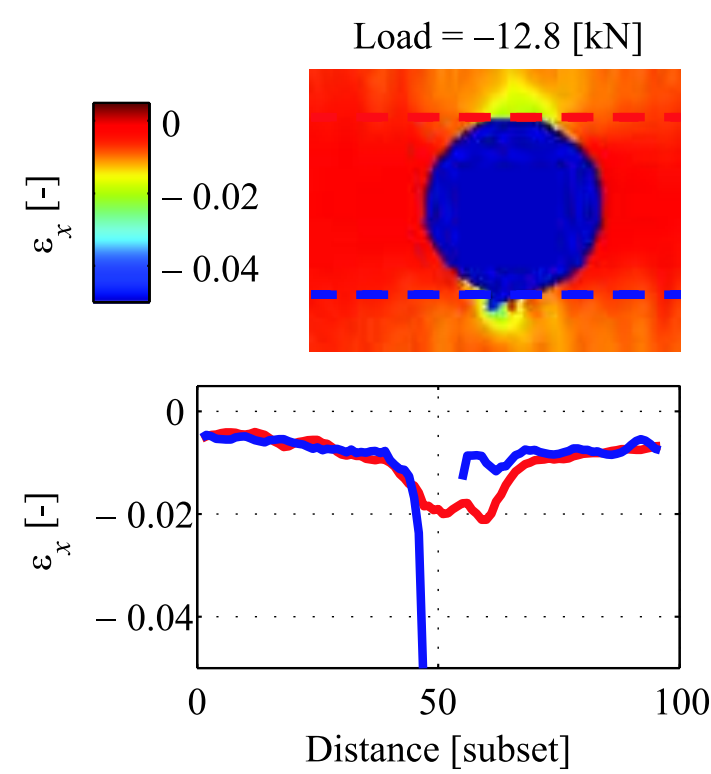

(a) Thin-ply lay-up 1 (asymmetric) laminate.
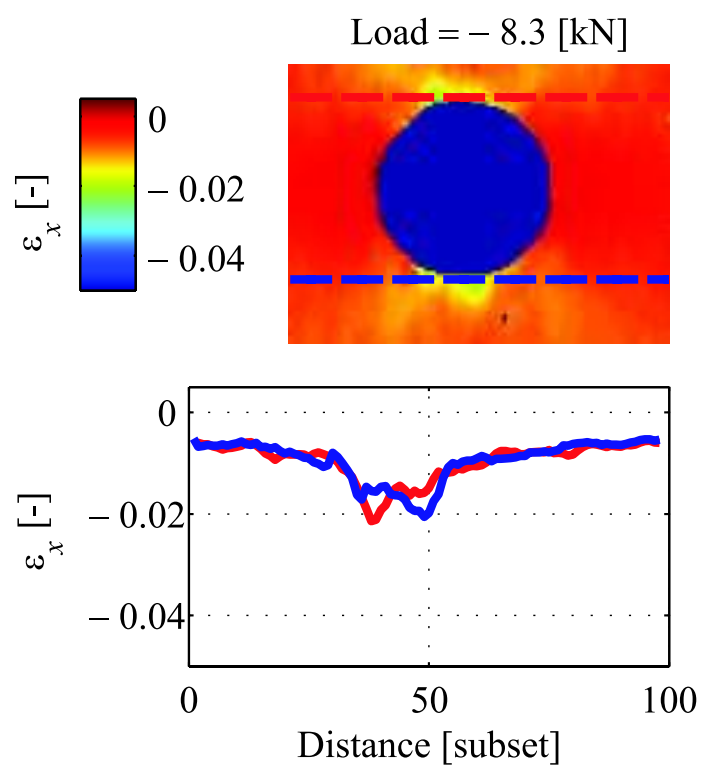

(b) Thin-ply lay-up 2 (symmetric) laminate.

Figure 20: Surface longitudinal strain fields at the maximum load for the thin-ply open-hole specimens with the $7 \mathrm{~mm}$ diameter hole loaded in compression. The loading direction is oriented horizontally. 

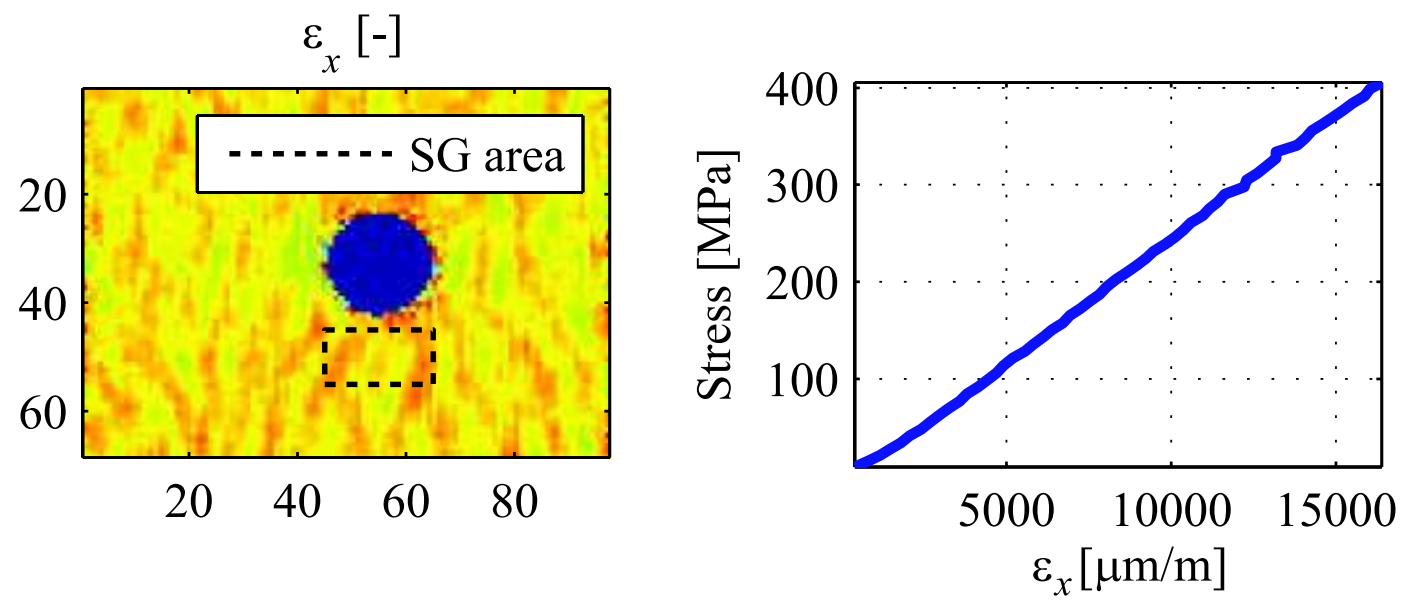

(a) Thin-ply lay-up 1 (asymmetric) laminate.
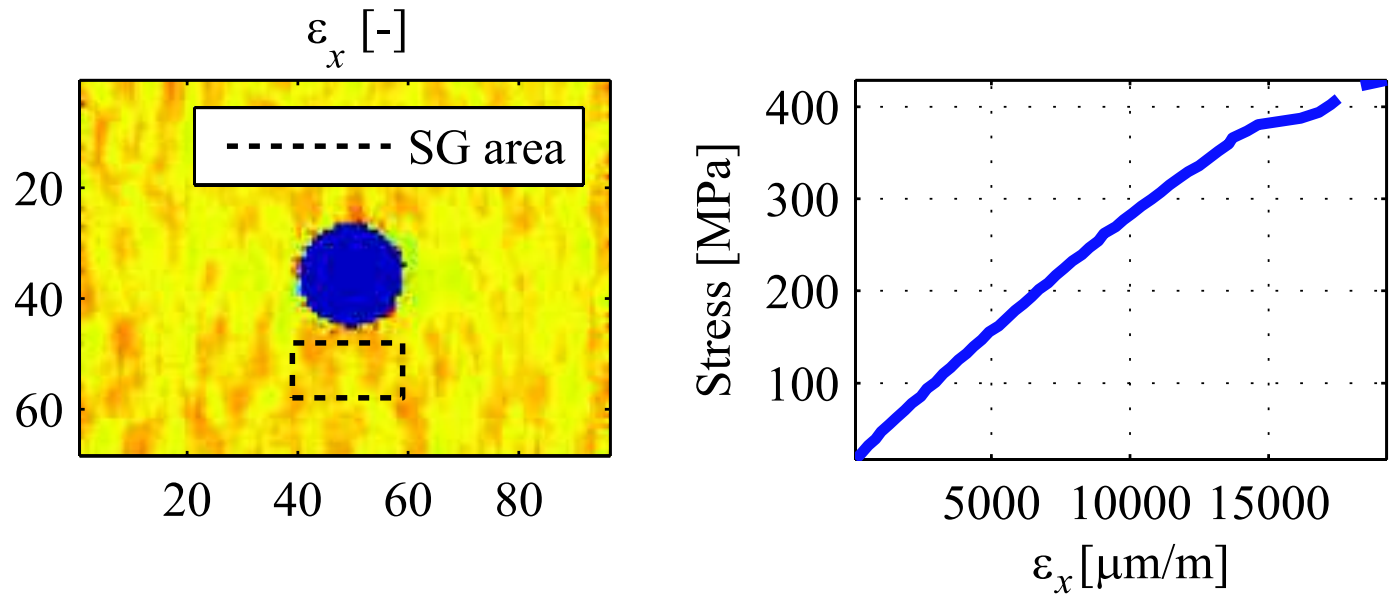

(b) Thin-ply lay-up 2 (symmetric) laminate.

Figure 21: Local stress-longitudinal strain relations for the thin-ply open-hole specimens with the 3 mm diameter hole loaded in tension. The loading direction is oriented horizontally. 

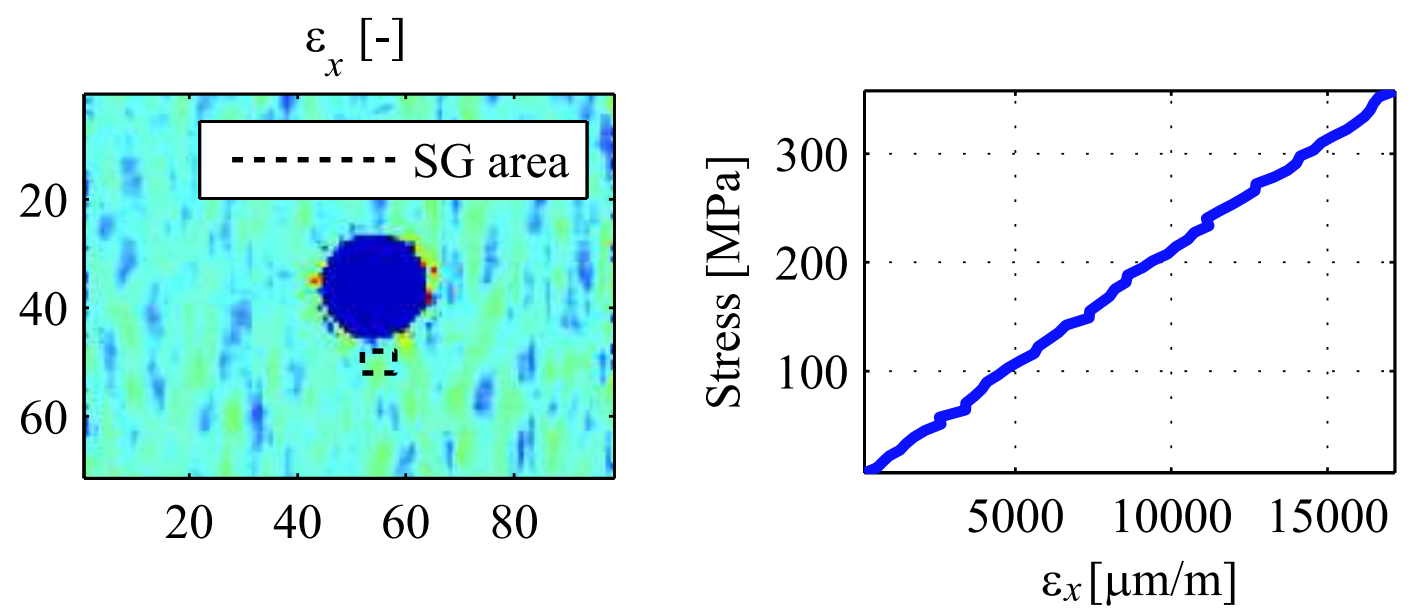

(a) Thin-ply lay-up 1 (asymmetric) laminate.
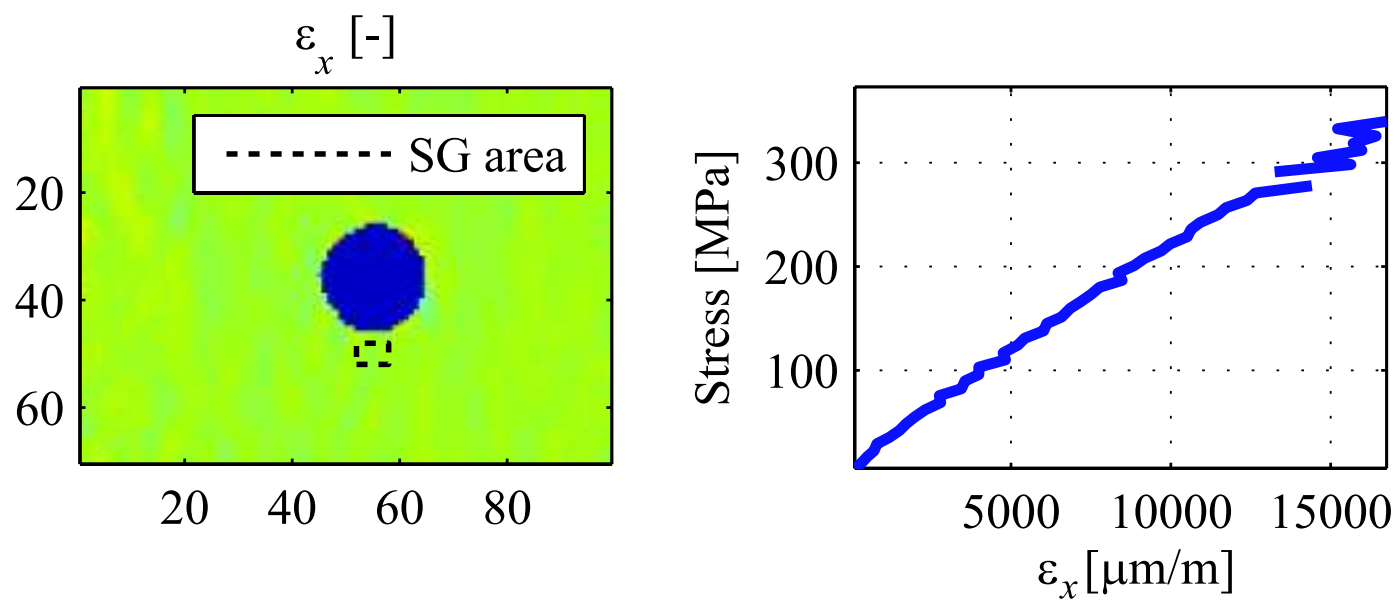

(b) Thin-ply lay-up 2 (symmetric) laminate.

Figure 22: Local stress-longitudinal strain relations for the thin-ply open-hole specimens with the $10 \mathrm{~mm}$ diameter hole loaded in tension. The loading direction is oriented horizontally. 


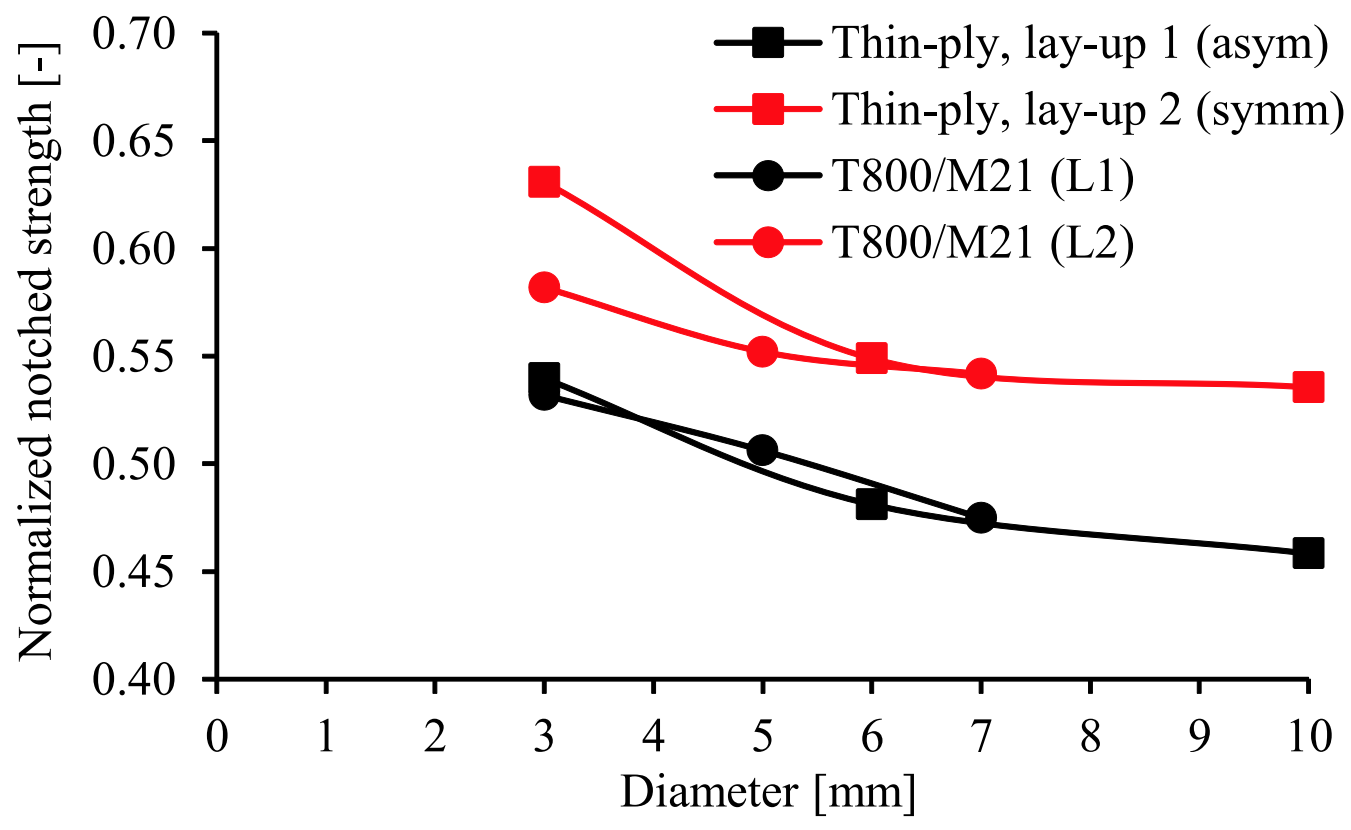

(a) Open-hole tension.

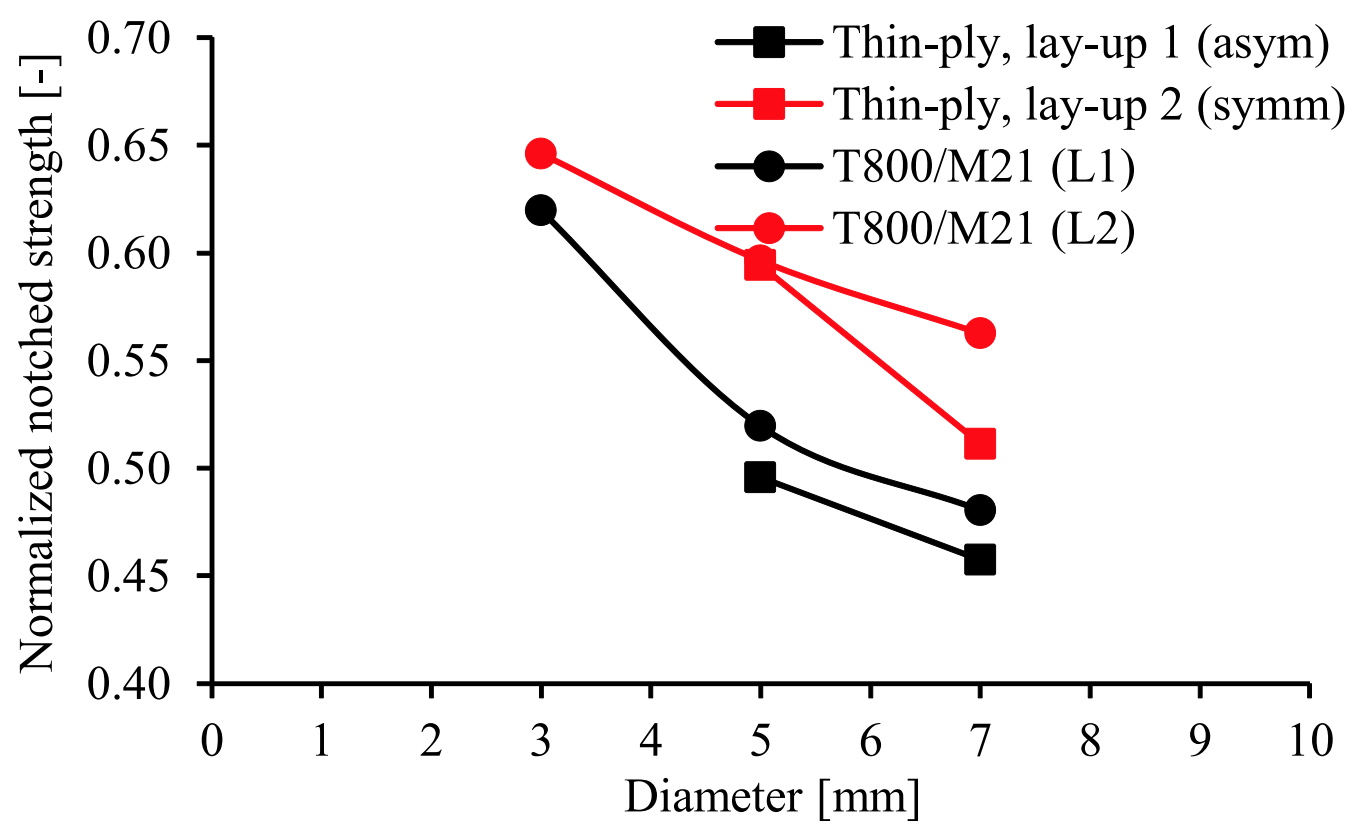

(b) Open-hole compression.

Figure 23: Identification of hole size effects in thin-ply laminates, and comparison with the $[90 / 45 / 0 /-45]_{3 \mathrm{~S}}(\mathrm{~L} 1)$ and $\left[90_{2} / 0_{2} / 45_{2} / 90_{2} / 0 / 45 /-45\right]_{\mathrm{S}}(\mathrm{L} 2) \mathrm{T} 800 / \mathrm{M} 21$ laminates. 


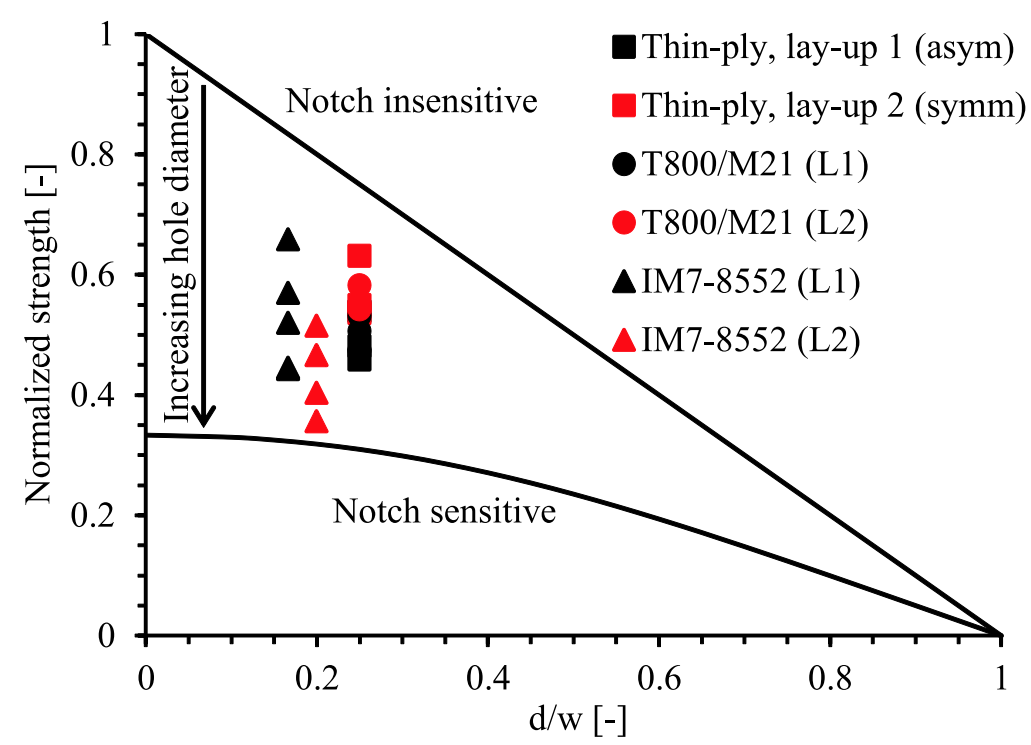

(a) Open-hole tension.

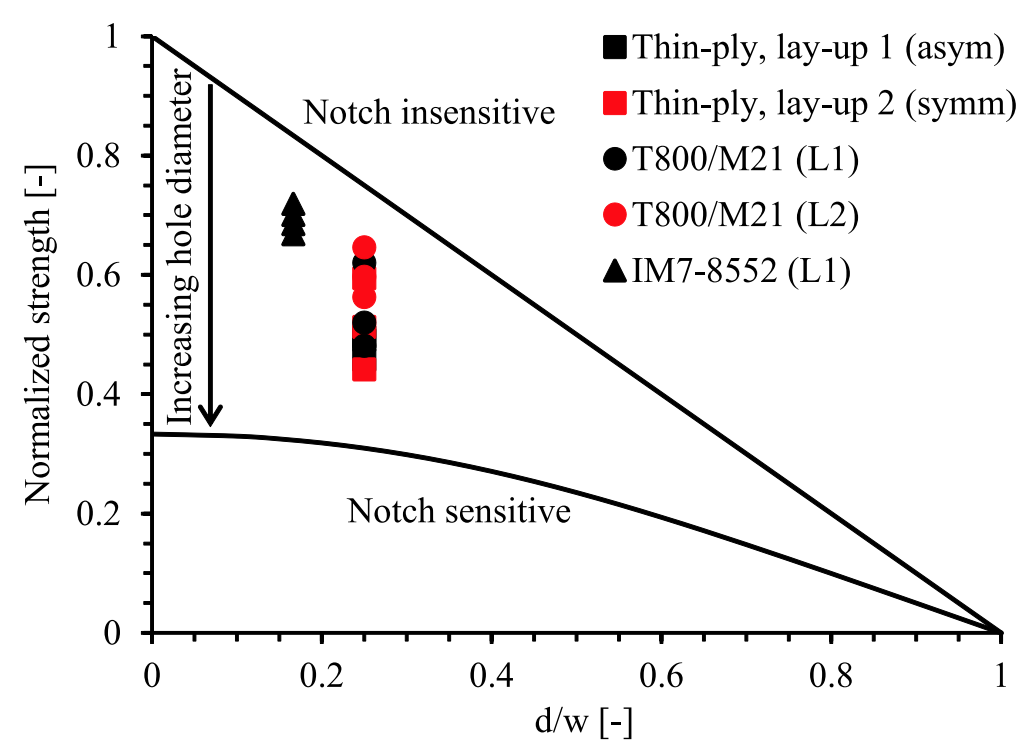

(b) Open-hole compression.

Figure 24: Analysis of the notch sensitivity of the thin-ply laminates. 


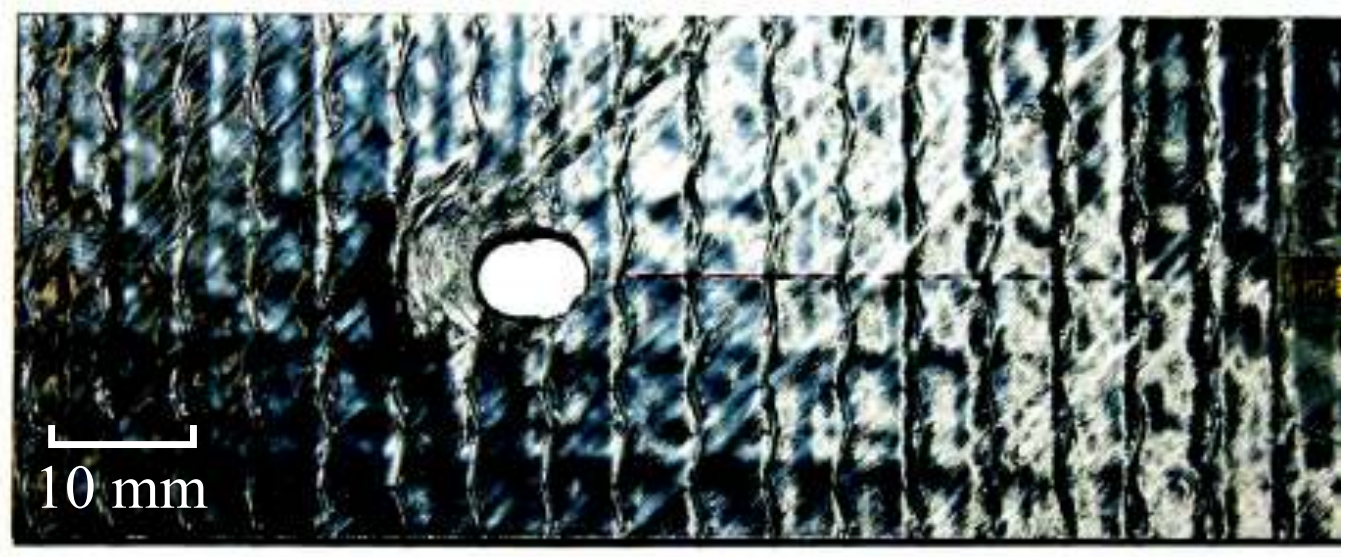

(a) Lay-up 1 (asymmetric) specimen.

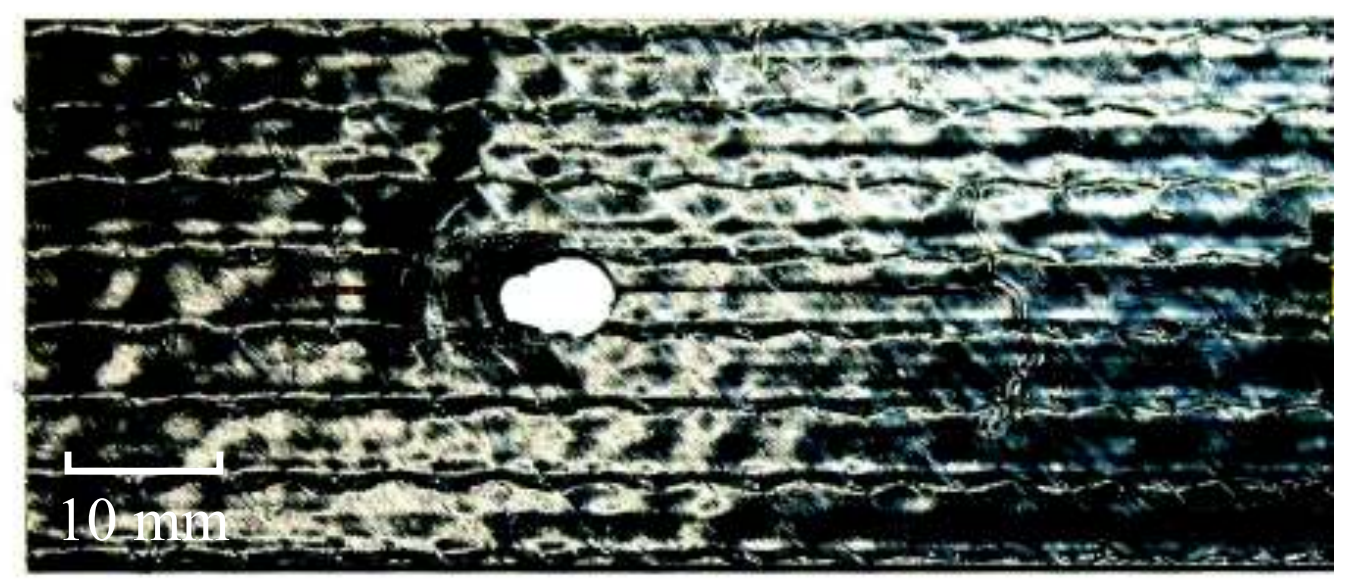

(b) Lay-up 2 (symmetric) specimen.

Figure 25: Failed bolt-bearing test specimens. 


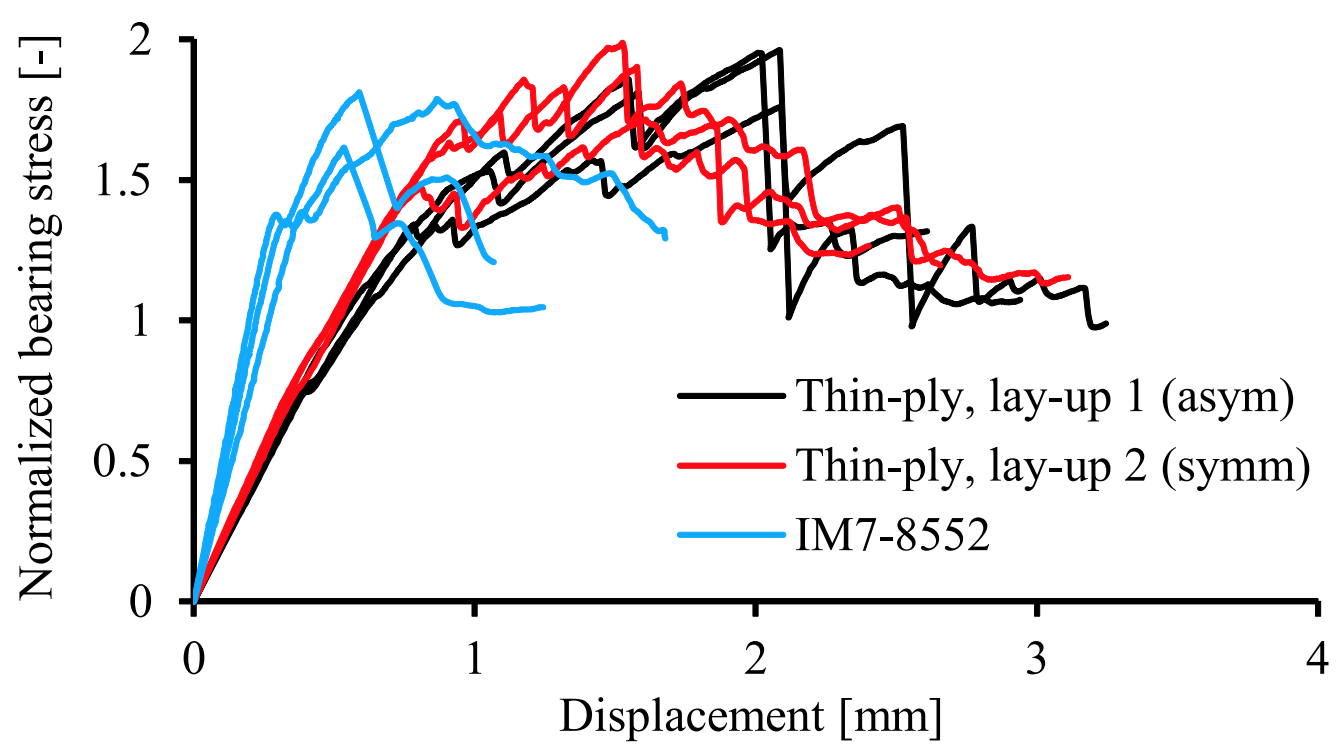

(a) Normalized bearing stress-displacement relations.

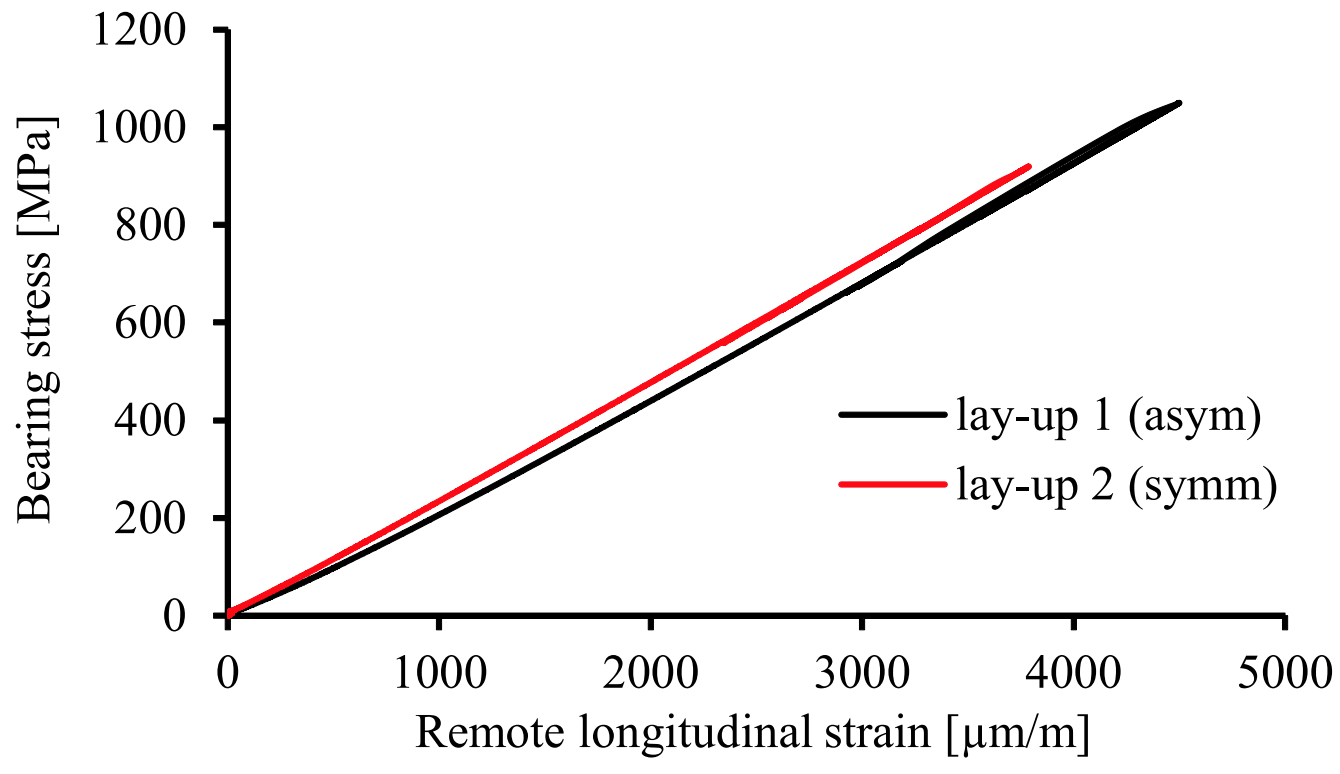

(b) Bearing stress-longitudinal strain relations.

Figure 26: Bolt-bearing test results. 


\section{List of Tables}

1 Ply properties of the thin-ply $\left(75 \mathrm{~g} / \mathrm{m}^{2}\right)$ C-PLY ${ }^{\mathrm{TM}} \mathrm{T} 700 \mathrm{NCF}$ from Chomarat. . . . . 47

2 Open-hole test matrix. . . . . . . . . . . . . . . . . . . 48

3 Plain strength test results for lay-up 1. . . . . . . . . . . . . . . . . 49

4 Plain strength test results for lay-up 2. . . . . . . . . . . . . . . . . 50

5 Center-notched test results for lay-up $1 . \ldots \ldots \ldots \ldots \ldots \ldots$

6 Center-notched test results for lay-up $2 \ldots \ldots \ldots \ldots \ldots \ldots$

$7 \quad$ Open-hole test results for lay-up $1 \ldots \ldots \ldots \ldots \ldots \ldots$

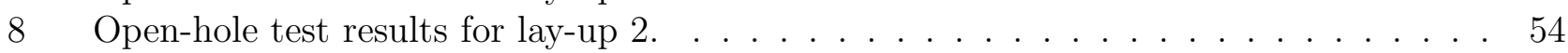

$9 \quad$ Normalized bearing strengths $(\mathrm{MPa}) \ldots \ldots \ldots \ldots \ldots \ldots$ 
Table 1: Ply properties of the thin-ply $\left(75 \mathrm{~g} / \mathrm{m}^{2}\right)$ C-PLY ${ }^{\mathrm{TM}} \mathrm{T} 700 \mathrm{NCF}$ from Chomarat.

\begin{tabular}{llrllrllr}
\hline$E_{1}$ & $(\mathrm{GPa})$ & 110.0 & $X_{T}$ & $(\mathrm{MPa})$ & 2300 & $S_{L}^{u d}$ & $(\mathrm{MPa})$ & 93 \\
$E_{2}$ & $(\mathrm{GPa})$ & 7.4 & $X_{C}$ & $(\mathrm{MPa})$ & 1500 & $V_{f}$ & $(\%)$ & $\approx 50$ \\
$G_{12}$ & $(\mathrm{GPa})$ & 4.2 & $Y_{T}^{\text {ud }}$ & $(\mathrm{MPa})$ & 66 & $E_{f}$ & $(\mathrm{GPa})$ & 210 \\
$\nu_{12}$ & & 0.3 & $Y_{C}$ & $(\mathrm{MPa})$ & 220 & $X_{f}$ & $(\mathrm{MPa})$ & 4900 \\
\hline
\end{tabular}


Table 2: Open-hole test matrix.

\begin{tabular}{lrrr}
\hline Load type & $W(\mathrm{~mm})$ & $d(\mathrm{~mm})$ & $L(\mathrm{~mm})$ \\
\hline \multirow{3}{*}{ Tension } & 12 & 3 & 250 \\
& 24 & 6 & 250 \\
& 40 & 10 & 250 \\
\hline \multirow{3}{*}{ Compression } & 8 & 2 & 305 \\
& 20 & 5 & 305 \\
& 28 & 7 & 305 \\
\hline
\end{tabular}


Table 3: Plain strength test results for lay-up 1.

\begin{tabular}{lrr}
\hline Property & Mean value & STDV \\
\hline$X_{T}^{L}(\mathrm{MPa})$ & 800.2 & 19.0 \\
$X_{C}^{L}(\mathrm{MPa})$ & 540.2 & 11.7 \\
$E^{L}(\mathrm{GPa})$ & 39.7 & - \\
$\nu_{12}^{L}$ & 0.27 & - \\
\hline
\end{tabular}


Table 4: Plain strength test results for lay-up 2.

\begin{tabular}{lrr}
\hline Property & Mean value & STDV \\
\hline$X_{T}^{L}(\mathrm{MPa})$ & 710.3 & 13.4 \\
$X_{C}^{L}(\mathrm{MPa})$ & 464.5 & 14.8 \\
$E^{L}(\mathrm{GPa})$ & 37.8 & - \\
$\nu_{12}^{L}$ & 0.22 & - \\
\hline
\end{tabular}


Table 5: Center-notched test results for lay-up 1.

\begin{tabular}{lrr}
\hline Property & Mean value & STDV \\
\hline $\bar{\sigma}_{T}^{\infty}(\mathrm{MPa})$ & 481.2 & 6.5 \\
$\mathcal{K}_{T}^{L}(\mathrm{MPa} \sqrt{\mathrm{m}})$ & 38.2 & 0.5 \\
$\mathcal{K}_{T}^{0}(\mathrm{MPa} \sqrt{\mathrm{m}})$ & 68.3 & - \\
$\bar{\sigma}_{C}^{\infty}(\mathrm{MPa})$ & 285.7 & 3.6 \\
$\mathcal{K}_{C}^{L}(\mathrm{MPa} \sqrt{\mathrm{m}})$ & 22.7 & 0.3 \\
$\mathcal{K}_{C}^{0}(\mathrm{MPa} \sqrt{\mathrm{m}})$ & 40.6 & - \\
\hline
\end{tabular}


Table 6: Center-notched test results for lay-up 2.

\begin{tabular}{lrr}
\hline Property & Mean value & STDV \\
\hline $\bar{\sigma}_{T}^{\infty}(\mathrm{MPa})$ & 475.9 & 8.6 \\
$\mathcal{K}_{T}^{L}(\mathrm{MPa} \sqrt{\mathrm{m}})$ & 37.8 & 0.7 \\
$\mathcal{K}_{T}^{0}(\mathrm{MPa} \sqrt{\mathrm{m}})$ & 67.5 & - \\
$\bar{\sigma}_{C}^{\infty}(\mathrm{MPa})$ & 299.7 & 12.6 \\
$\mathcal{K}_{C}^{L}(\mathrm{MPa} \sqrt{\mathrm{m}})$ & 23.8 & 1.0 \\
$\mathcal{K}_{C}^{0}(\mathrm{MPa} \sqrt{\mathrm{m}})$ & 42.5 & - \\
\hline
\end{tabular}


Table 7: Open-hole test results for lay-up 1.

\begin{tabular}{lrrr}
\hline Property & $d(\mathrm{~mm})$ & Mean value & STDV \\
\hline $\bar{\sigma}_{T}^{\infty}(\mathrm{MPa})$ & 3 & 431.8 & 16.1 \\
$\bar{\sigma}_{T}^{\infty}(\mathrm{MPa})$ & 6 & 384.9 & 14.6 \\
$\bar{\sigma}_{T}^{\infty}(\mathrm{MPa})$ & 10 & 366.8 & 9.7 \\
$\bar{\sigma}_{C}^{\infty}(\mathrm{MPa})$ & 5 & 267.8 & 3.2 \\
$\bar{\sigma}_{C}^{\infty}(\mathrm{MPa})$ & 7 & 247.1 & 10.8 \\
\hline
\end{tabular}


Table 8: Open-hole test results for lay-up 2.

\begin{tabular}{lrrr}
\hline Property & $d(\mathrm{~mm})$ & Mean value & STDV \\
\hline $\bar{\sigma}_{T}^{\infty}(\mathrm{MPa})$ & 3 & 448.1 & 17.1 \\
$\bar{\sigma}_{T}^{\infty}(\mathrm{MPa})$ & 6 & 389.9 & 7.4 \\
$\bar{\sigma}_{T}^{\infty}(\mathrm{MPa})$ & 10 & 380.4 & 16.6 \\
$\bar{\sigma}_{C}^{\infty}(\mathrm{MPa})$ & 5 & 276.0 & 12.6 \\
$\bar{\sigma}_{C}^{\infty}(\mathrm{MPa})$ & 7 & 237.6 & 5.4 \\
\hline
\end{tabular}


Table 9: Normalized bearing strengths (MPa).

\begin{tabular}{lrr}
\hline Laminate & Mean value & STDV \\
\hline Thin-ply lay-up 1 & 1.410 & 0.086 \\
Thin-ply lay-up 2 & 1.641 & 0.119 \\
IM7-8552 & 1.372 & 0.013 \\
\hline
\end{tabular}

